\title{
Infectious Diseases: The Role of the Healthcare Professional
}

\author{
Felicity Nicholson
}

\section{Learning Objectives}

Explanation of the importance of taking standard precautions with all patients.

Treatment of an 'at risk exposure' and organization of a management plan.

Demonstrate the ability to provide advice to the police with regard to the effective management of the common infectious diseases seen in custody.

\section{Introduction}

Infections have plagued healthcare professionals (HCPs) for centuries, both in the diagnosis of the specific diseases, and the identification and subsequent management of the causative agents. There is a constant need for information as new organisms emerge, existing ones develop resistance to current drugs or vaccines, and there are changes in epidemiology and prevalence. In the twenty-first century, obtaining this information has never been more important. Population migration, and the relatively low cost of flying, means that unfamiliar infectious diseases may be brought into industrialized countries. An example of this was an outbreak of severe acute respiratory syndrome (SARS), which was first recognized in 2003. Despite modern technology and a huge input of money, it took months for the agent to be identified, a diagnostic test to be produced, and a strategy for disease reporting and isolation to be established.

A further example of how population migration can result in the spreading of disease was with the appearance of swine influenza A (H1N1). In March 2009, the first case was reported in Mexico; by June 2009, over 22,000 cases had been reported in 70 countries, thus fulfilling the criteria for a pandemic. Challenges ensued with decisions about treatment and then the distribution and administration of specific vaccine. More recent examples include the discovery of Corona virus Mers CoV

F. Nicholson $(\bowtie)$

Trailfinders Travel Clinic, London, UK 
which emerged predominantly from the Middle East in 2012 and spread to many countries. In 2014 there was an Ebola outbreak in West Africa which lead to cases being transferred to Europe and the USA.

There is no doubt that other new and fascinating diseases will continue to emerge. For the healthcare professional dealing with infections presents two main problems. First, managing detainees or police personnel who have contracted a disease and may be infectious or unwell, and second, handling complainants of assault, including police officers, who have potentially been exposed to an infectious disease. The latter can be distressing for those involved, compounded in part from an inconsistency of management guidelines, if indeed they exist.

With the advent of human rights legislation, increasing pressure is being placed on HCPs with regard to consent and confidentiality of the detainee. Therefore, it is prudent to pre-empt such situations before the consultation begins by obtaining either written or verbal consent from the detainee to allow certain pieces of information to be disclosed. If he/she does not agree, then the HCP must decide whether withholding relevant details will endanger the lives or health of those working within custody or others with whom they may have had close contact (whether or not deliberate). Issues of consent and confidentiality are discussed in detail in Chap. 2.

Adopting standard precautions with all detainees will decrease the risk to staff of acquiring such diseases and will help to stop unnecessary overreaction and unjustified disclosure of sensitive information. For victims of violent or sexual assault, a more open-minded approach is needed (see also Chap. 3). If the assailant/suspect is known, then it may be possible to make an informed assessment of the risk of certain diseases by ascertaining their lifestyle and where possible by asking permission to test for certain diseases. If, however, the assailant is unknown, then this is not possible and so it is best to assume they are infected. This chapter aims to highlight the most common infections encountered by the healthcare professional. It aims to dispel "urban myths" and provide a sensible approach for achieving effective management.

\section{Standard Precautions}

The risk of exposure to infections, in particular to blood-borne viruses (BBVs), can be minimized by adopting measures that are considered good practice in the UK, the USA and Australia [1-3]. The Guidance for Clinical Health Care Workers: Protection against infection with blood borne viruses, (DOH 1998) contains standard precautions. The aim of adopting standard precautions is to prevent transmission of BBVs by considering that blood and other body fluids are potentially infectious. It means never assuming that there is no risk. If every patient is assumed to be potentially infected with a blood borne infection the same precautions to prevent exposure should be used for every procedure.

Healthcare professionals should wash their hands before and after contact with each detainee or victim. A laminated copy of good hand washing techniques (e.g. from the National Patient Safety Agency) should be displayed by the sink in the 
medical room. Liquid soap from a wall mounted dispenser should be used routinely. Alcohol hand rub can be used as an alternative if hands are dry and physically clean. It should not be used if the patient has had diarrhea in the last $48 \mathrm{~h}$ as it is not effective against Norovirus or Clostridium difficile. Police officers should be encouraged to wash their hands after exposure to body fluids or excreta. All staff should wear gloves when exposure to body fluids, mucous membranes or nonintact skin is likely. Gloves should also be worn when cleaning up body fluids or handling clinical waste including contaminated laundry. Only single-use gloves which are powder free should be used and must conform to the requirements of British and EN standards and be CE marked or equivalent [1-3]. A synthetic alternative conforming to the same standards should also be available for those allergic to latex e.g. nitrile.

All staff should cover any fresh wounds (less than $24 \mathrm{~h}$ old), open skin lesions or breaks in exposed skin with a waterproof dressing. Single gloves have been shown to remove $86 \%$ of surface blood and therefore reduces the risk of acquiring a BBV infection. Doubling gloving removes even more. Gloves should be worn when taking blood, providing this does not reduce manual dexterity and therefore increase the risk of accidental percutaneous injury.

A designated person should be allocated to ensure the clinical room is kept clean and sharps containers and clinical waste bags should be removed on a regular basis. Clinical waste must be disposed of in "hazard bags" and should never be over-filled. After use they should be double-bagged and sealed with "hazard tape". The bags should be placed in a locked designated waste disposal store and removed by a professional company. When cells are contaminated with body fluids, a professional cleaning company should be called to attend as soon as possible. Until such time, the cell should be deemed "out of action".

Ideally there should be a designated infection control lead who has the overall responsibility of auditing the premises and ensuring that they meet infection control standards.

\section{Sharps Awareness}

The main risk of sharps injury is the potential acquisition of the major blood borne viruses (BBV) hepatitis B, hepatitis C, and HIV. Other infectious agents can also be transmitted through sharp injuries including but not limited to Human $\mathrm{T}$ Lymphotrophic retroviruses (HTLVI \& II), Cytomegalovirus, and Epstein Barr virus.

Whether or not an infection is acquired depends on a number of factors including the person's immune system, the type of sharp involved, the depth and site of the sharp injury and how infectious the blood was at the time of the injury.

Whilst the number of sharp injuries leading to infection is small, there are the direct costs of the medication to consider alongside the psychological impact which is harder to quantify. There may also be side effects from the medication and time lost from work. 
There is a legal requirement in the UK under the Environmental Protection Act (1990) and the Control of Substances Hazardous to Health Regulations 2002 (COSHH) to dispose of sharps in an approved container. In the USA, the Division of Healthcare Quality Promotion (DHQP) on the Centers for Disease Control and Prevention (CDC) website provides similar guidance. Further guidance can also be find in the 'Stop Sticks' campaign run by the National Institute for Occupational Safety and Health (NIOSH).

In custody where sharps containers are transported off site, they must be of an approved type and the correct UN approved color. In the UK, such a requirement is contained within the Carriage of Dangerous Goods (Classification, Packaging and Labelling) and Use of Transportable Pressure Receptacles Regulations 2009. These measures help to minimize the risk of accidental injury. Further precautions include wearing gloves when handling sharps and never bending, breaking or re-sheathing needles before disposal. Sharps bins should never be more than three quarters full, they should be secured to the wall when in use and should be placed at a safe height for those using it to minimize the risk of inoculation injuries when disposing of the sharps.

\section{Contaminated Bedding}

Any bedding that is visibly stained with body fluids should be handled with gloves. There are only three acceptable ways of dealing with contaminated bedding:

1. Laundering with a detergent at a minimum temperature of $71^{\circ} \mathrm{C}\left(160{ }^{\circ} \mathrm{F}\right)$ or at a lower temperature $\left(22-50{ }^{\circ} \mathrm{C}\right)$ with water containing detergent and 50-150 ppm of chlorine bleach.

2. Dry cleaning at elevated temperatures/dry cleaning cold followed by steam pressing.

3. Incineration.

It is not considered acceptable practice to share bedding between detainees.

\section{Other Measures}

It is not necessary for staff to wear masks or protective eyewear in the custodial setting as the risk of infection is low. However, single use eyewash should be available in the clinical room or contained in other first aid kits located within the police station in case of accidental exposure. Contact lenses should be removed prior to eye washing.

\section{Formulation of Guidelines}

An example of good practice is contained within the UK Health Department's 1998 document [1] which states "that it is the responsibility of Health Authorities, Health Boards and NHS Trusts to create their own local guidelines to prevent the spread of 
BBVs in the health care setting". The Health and Social Care Act 2008 Code of Practice on the prevention and control of infections and related guidance also sets out the standards for the NHS and other regulated health care providers. Such guidelines may not exist in other work places. If this is the case, then they should be formulated as soon as possible. It is also prudent to pre-arrange a system of referral with the nearest hospital that has an Emergency Department, a Genito-Urinary Department and access to a Specialist. The latter may be a consultant in Virology, Microbiology, Infectious Diseases or Genito-Urinary Medicine. Similar guidance in the USA can be found in "The Guideline for Infection Control in Health Care Personnel" [4].

Most exposures to staff usually result from a failure to follow accepted practice; however, accidents can happen no matter how much care is taken. All healthcare professionals working in custody should understand what constitutes a risk and should have had relevant infection control training. This involves taking a detailed history of the incident, including the type of exposure, the body fluids involved and when it occurred.

This information could help to allay unnecessary anxiety from the outset and will ensure that the recipient of the exposure is referred, if appropriate, to the designated hospital at the earliest opportunity. Knowledge of precise treatment protocols is not required, but it is helpful to be able to explain to the recipient what to expect. For example, he or she will be asked to provide a voluntary baseline blood sample for storage and a number of follow-up samples for testing depending on the nature of the exposure. This is especially relevant for hepatitis B (HBV), hepatitis $\mathrm{C}$ (HCV) and human immunodeficiency virus (HIV). Most usually, this will be complete by 12 weeks, but on occasion testing may be extended to 6 months after the incident.

Sexual assault complainants should ideally be referred to specialist centers, if available. A police station should only be used as a last resort because the environment is often hostile and there is no ready access to the necessary treatment and ongoing management (see Chap. 3).

\section{Routes of Transmission}

Organisms may utilize more than one route. For ease of understanding, the infections discussed in this chapter are classified according to their primary route, i.e. transmission through blood and body fluids; through contact with lesions or organisms; through the respiratory route; and through the fecal-oral route.

\section{Transmission Through Blood and Body Fluids}

The BBVs which present most cross-infection hazard to staff or victims are those associated with persistent viral replication and viremia. These include hepatitis B (HBV), hepatitis C (HCV), hepatitis D (HDV), and human immunodeficiency virus (HIV). 


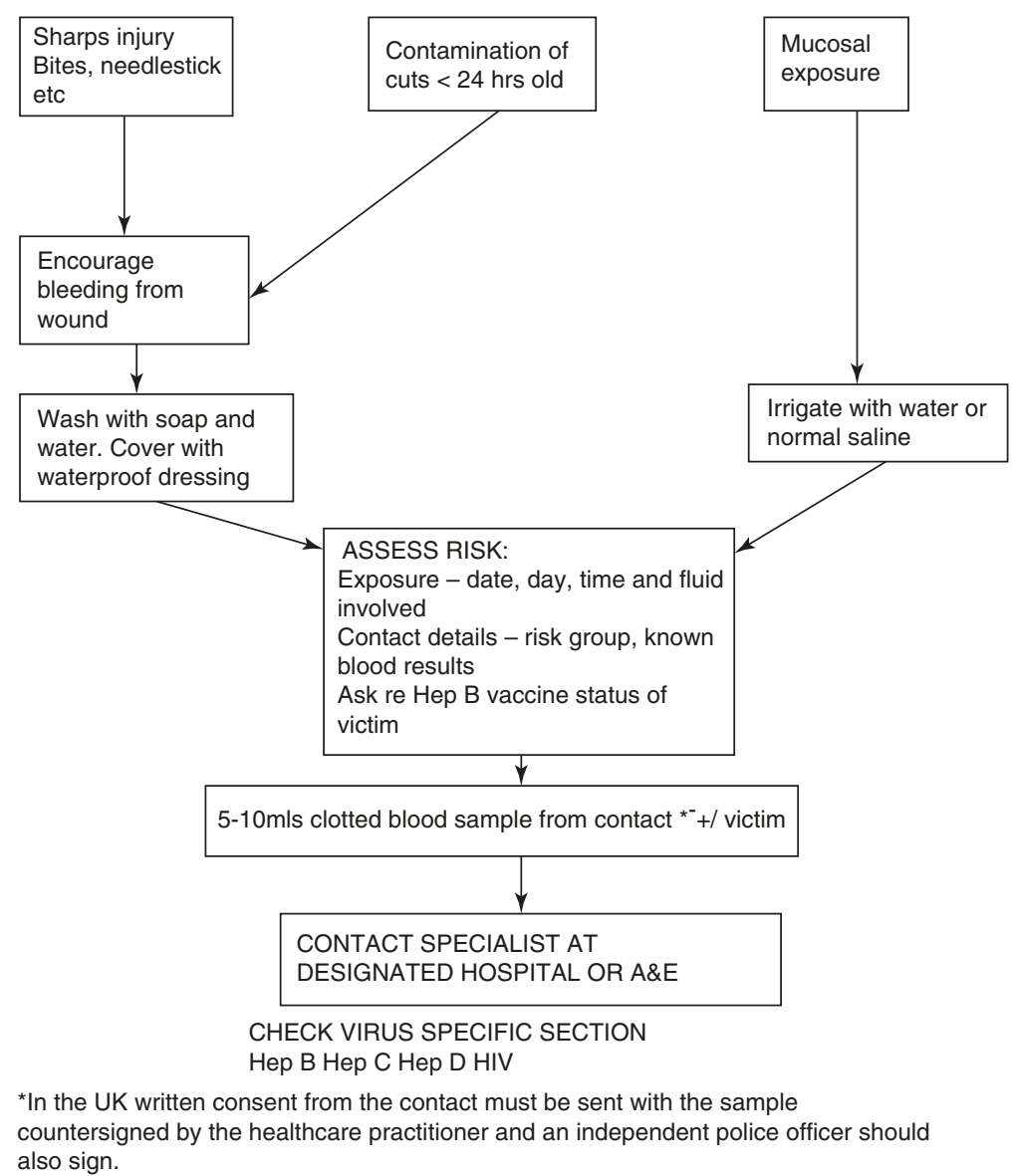

Fig. 10.1 Immediate management following occupational exposure to blood-borne viruses (BBVs)

In general, risks of transmission of BBVs arise from the possible exposure to blood or other body fluids. The degree of risk varies with the virus concerned and will be discussed under the relevant sections. Figure 10.1 illustrates the immediate management following a percutaneous injury, mucocutaneous exposure, or exposure through contamination of fresh cuts or breaks in the skin.

\section{Hepatitis B}

\section{Epidemiology and Prevalence}

HBV is endemic throughout the world with populations showing a varying degree of prevalence. Approximately 2000 million people have been infected with HBV. In 
Table 10.1 Prevalence of chronic hepatitis B by world areas

\begin{tabular}{l|l}
\hline Prevalence & Areas \\
\hline Low $<2 \%$ & $\begin{array}{l}\text { Most of western Europe including the UK, North America, Australia } \\
\text { (excluding the Aborigines), New Zealand }\end{array}$ \\
\hline $\begin{array}{l}\text { Intermediate } \\
(2-8 \%)\end{array}$ & $\begin{array}{l}\text { Mediterranean, the Amazon Basin, most of the Middle East, japan, the } \\
\text { Indian Sub Continent and southern parts of Eastern and Central Europe }\end{array}$ \\
\hline High $>8 \%$ & Sub Saharan Africa, most of Asia and the Pacific Islands \\
\hline
\end{tabular}

2015 there were 257 million people living with chronic infection world-wide [5]; and world-wide in that same year HBV killed 887,000 people.

With the development of a safe and effective vaccine in 1982, the World Health Organization (WHO) recommended that $\mathrm{HBV}$ vaccine should be incorporated into national immunization programmes by 1995 in those countries with a chronic infection rate of $8 \%$ or higher and into all countries by 1997. In 2015 global coverage with the three doses of hepatitis B vaccine in infancy reached $84 \%$. However coverage with the first birth dose of vaccine remains low at 39\%. Meaning that some of the poorer countries were not meeting their targets [5].

In the United Kingdom, the overall prevalence of chronic HBV is around $0.1-0.5 \%$ [6] which according to the WHO classification based on the prevalence of HBsAg is low (less than 2\%). Other low prevalence areas include most of Western Europe and North America. High prevalence which is found in sub Saharan Africa, most of Asia and the Pacific Islands has a prevalence of more than $8 \%$ (see Table 10.1).

\section{Symptoms and Complications}

The incubation period is approximately 40-160 days. As the name suggests, the virus primarily affects the liver. Many people with acute infection have a sub clinical or flu-like illness. Typical symptoms include malaise, anorexia, nausea, mild fever, and abdominal discomfort and may last from 2 days to 3 weeks before the insidious onset of jaundice. Joint pain and skin rashes may also occur due to immune complex formation. Infections in the newborn are usually asymptomatic.

The majority of patients with acute HBV make a full recovery and develop immunity. Following acute infection, about 1 in 300 patients develop liver failure, which may result in death.

Chronic infection develops in around $90 \%$ of neonates, about $20-50 \%$ of children infected between the ages of 1-5 years old and around 5\% of adults. Neonates and children are usually asymptomatic. Adults may have only mild symptoms or may also be asymptomatic. Approximately $20-25 \%$ of chronically infected individuals (depending on age of acquisition) will develop cirrhosis over a number of years. This may also result in liver failure or other serious complications including hepatocellular carcinoma, though the latter is rare. The overall mortality rate of $\mathrm{HBV}$ is estimated at less than $5 \%$. 
Table 10.2 Significance of markers

\begin{tabular}{l|l|l|l}
\hline Name & Infectivity & Immunity & Risk following needle stick (\%) \\
\hline HBsAg & Yes & No & Only marker $=10-20$ \\
\hline HBeAg & Yes & No & With HBsAg $=30-40$ \\
\hline HBeA & Yes & Yes & With HBsAg $\leq 10$ \\
\hline HBCA & No & Yes & 0 \\
\hline HBSA & No & Yes & 0 \\
\hline
\end{tabular}

$H B s A g$ Hepatitis B surface antigen, HbeAg hepatitis B e antigen, HBeA hepatitis B e antibody, $H B C A$ hepatitis B core antibody, $H B S A$ hepatitis B surface antibody

\section{Period of Infectivity}

A person is deemed infectious if hepatitis B surface antigen (HBsAg) is detected in the blood. In the acute phase of the illness, this can be for as long as 6 months. By definition, if HBsAg persists for after this time then the person is deemed a carrier. Carriers are usually infectious for life. The degree of infectivity depends on the stage of disease and the markers present in Table 10.2.

\section{Routes of Transmission}

The major routes include: parenteral (e.g. needlestick injuries, bites (rare), blood transfusions (rare in the UK as blood donors and donations are screened), tattooing, acupuncture and dental procedures, where equipment is inadequately sterilised); mucous membrane exposure (including mouth, eyes and genital mucous membranes including vaginal and anal intercourse), through perinatal transmission from mother to child and contamination of broken skin (especially when $<24 \mathrm{~h}$ old).

\section{At-Risk Groups}

HBV is an occupational hazard for anyone who may come into contact with blood or bloodstained body fluids through the routes described above. Saliva alone may transmit HBV. The saliva of some people infected with HBV has been shown to contain HBV-DNA concentrations $1 / 1000-1 / 10,000$ of that found in their serum [7]. This is especially relevant for penetrating bite wounds. Infection following exposure to other body fluids, e.g. bile, urine, feces and CSF, has never been demonstrated unless the fluids are contaminated with blood.

In 2016 in England there were 453 reported cases of acute or probable acute cases of hepatitis B [8]. The prevalence of acute hepatitis B in London was $1.7 / 100,000$ population compared with $0.82 / 100,000$ nationally. Where a route of transmission was identified, in $64.6 \%$ cases the mode of transmission was through heterosexual exposure. Men who have sex with men accounted for $14 \%$ of the cases. However, only $36 \%$ had information about the associated exposure. None the less the data presented suggests that the number of cases of acute hepatitis B in PWID has remained low in 2016. Periodic surveys in PWID show that the hepatitis B 
prevalence is around 1 in 500 [9] This is thought to be in part due to increased awareness, and self-reported hepatitis B vaccine uptake. In 2016 about $75 \%$ of PWID reported having hepatitis B vaccine, but this level is no longer increasing. Uptake is especially low in younger age groups and amongst new injectors [8].

Evidence has shown that the virus may also be spread among members of a family through close household contact. This is thought to be through kissing, sharing toothbrushes, razors, bath towels, etc. [10-12]. This route of transmission probably applies to institutionalized patients.

In the Public Health England Health and Justice Annual Review 2017/2018 [13] the prevalence of blood-borne viruses was four times higher in the prison population than in the general population. Hepatitis B prevalence was reported as $0.6 \%$ in the prison population versus $0.16 \%$ in the general population.

HBV can be transmitted vertically from mother to baby during the perinatal period. Around $80 \%$ of babies born to mothers who have either acute or chronic HBV become infected and most will develop chronic HBV. This has been limited by the administration of HBV vaccine to the neonate. In industrialized countries all antenatal mothers are screened for HBV. Vaccine is given to the neonate ideally within the first $12 \mathrm{~h}$ of birth and at least two further doses are given at designated intervals. The WHO recommends this as a matter of course for all women in countries where prevalence is high. However, the practicalities of administering vaccine that has to be stored at the correct temperature and limited access to medical care mean that there is a significant failure of vaccine uptake and response.

\section{Disease Prevention}

In industrialized countries, $\mathrm{HBV}$ vaccination is recommended for those deemed at risk of acquiring the disease

1. Through occupational exposure

2. Homosexual/bisexual men

3. People who inject drugs

4. Female commercial sex workers

5. Patients with chronic renal or hepatitis disease

6. Sexual partners of people with acute or chronic HBV including victims of sexual assault

7. Family members of people with acute or chronic HBV

8. Newborn babies whose mothers are infected with HBV. If the mother is $\mathrm{HBeAg}$ positive, then HBV-specific immunoglobulin (HBSIG) should be given at the same time as the first dose of vaccine

9. If the baby is born to an HBV negative mother but is going home to another HBV positive household member they should receive one dose of Hepatitis B vaccine before leaving hospital and then continue on the routine schedule [10]

10. Institutionalized patients and inmates of custodial institutions.

11. As of October 2017, hepatitis B has been incorporated in a hexavalent vaccine which is given to all babies born in the UK with doses being at given at 2, 3 and 4 months 
Ideally, HBV vaccine should be administered prior to exposure. For most adult and child risk groups an accelerated schedule is used. Three doses of vaccine are given at 0,1 and 2 months because it has been shown that there are higher completion rates particularly amongst those who are less compliant (e.g. PWID). The improved compliance will probably offset against the slightly reduced immunogenicity of this accelerated schedule compared with the 0,1 and 6 month schedule. Giving a booster after a year where possible will provide a similar immune response.

If the individual is considered to be at more immediate risk then a super accelerated course can be used with three doses given on day 0,7 and 21. A fourth dose would be given 12 months after the first dose to ensure long term protection. This schedule is licensed in adults over 18 and is particularly useful for people travelling to areas of high endemicity, prisoners and PWID. It can also be used off license for those aged 16-18 where it is important to provide rapid protection and achieve maximum compliance.

It is believed that in immunocompetent individuals following a successful vaccination course that immunity against hepatitis B lasts for around 30 years. The WHO in 2017 stated that there was no need for a booster dose of hepatitis B vaccine in routine immunization programmes.

For health care workers the $0,1,6$ month schedule is preferred unless they are going to be engaging in exposure prone procedures in which case a more rapid schedule can be used. A blood test should be done 8-12 weeks after the third dose of vaccine. If the titre is $>10 \mathrm{miU} / \mathrm{mL}$ then an adequate response has been achieved. In the UK a further dose of vaccine is given at 5 years. In the USA, if an initial adequate response has been achieved, then no further doses of vaccine are considered necessary for Health care workers.

Patients with chronic renal failure or who are on hemodialysis may have poor immunological memory and require further boosts if titres fall below $10 \mathrm{miU} / \mathrm{mL}$.

\section{Post Exposure Prophylaxis}

Hepatitis B vaccine administration after exposure varies according to the timing of the incident, the degree of risk involved, and whether the individual has already been partly or fully vaccinated as can be seen in Table 10.3 below.

Hepatitis B specific Immunoglobulin (HSIG) may be used either alone or in conjunction with vaccine. The exact dose given is age-dependent, but must be administered by deep intra-muscular injection in a different site from the vaccine. In an adult, this is usually into the gluteus muscle. If HBIG is being given together with hepatitis B vaccine then it should be given at the same time, ideally within $24 \mathrm{~h}$ of an exposure, but can be considered up to 7 days after. It is also used for neonates born to mothers who are $\mathrm{HBeAg}$-positive where the risk of vertical transmission is greatest.

Between 5\% and 10\% of adults fail to respond to the routine schedule of vaccine. A further full course of vaccine should be tried before deeming them "non-responders". It is worth considering using Twinrix as there is evidence that the combination of 
Table 10.3 Hepatitis B prophylaxis following exposure-adapted from the Green book Chap. 18 [14]

\begin{tabular}{|c|c|c|c|}
\hline \multirow[b]{2}{*}{$\begin{array}{l}\text { HBV status of } \\
\text { person exposed }\end{array}$} & \multicolumn{3}{|l|}{ Significant exposure } \\
\hline & Source HBsAg positive & Unknown source & Source HBsAg - ve \\
\hline Unvaccinated & $\begin{array}{l}\text { Accelerated course of } \\
\text { Hep B vaccine plus } \\
\text { HBSIG with first dose }\end{array}$ & $\begin{array}{l}\text { Accelerated course of } \\
\text { Hep B vaccine }\end{array}$ & $\begin{array}{l}\text { Consider course of } \\
\text { hepatitis B vaccine } \\
\text { especially if at } \\
\text { continued risk }\end{array}$ \\
\hline $\begin{array}{l}\text { Partially } \\
\text { vaccinated }\end{array}$ & $\begin{array}{l}\text { One dose of vaccine sat } \\
\text { and then finish the course }\end{array}$ & $\begin{array}{l}\text { One dose of vaccine } \\
\text { stat and then finish } \\
\text { the course }\end{array}$ & $\begin{array}{l}\text { Consider completing } \\
\text { the course }\end{array}$ \\
\hline $\begin{array}{l}\text { Fully vaccinated } \\
\text { with primary } \\
\text { course }\end{array}$ & $\begin{array}{l}\text { Booster dose of hep B } \\
\text { vaccine if last dose } \\
\geq 1 \text { year ago }\end{array}$ & $\begin{array}{l}\text { Consider booster dose } \\
\text { of hep B vaccine if } \\
\text { last dose } \geq 1 \text { year ago }\end{array}$ & $\begin{array}{l}\text { No HBV prophylaxis. } \\
\text { Reassure }\end{array}$ \\
\hline $\begin{array}{l}\text { Known non } \\
\text { responder } \\
\text { Anti HBS }<10 \text { iu } \\
1-2 \text { months after } \\
\text { vaccination }\end{array}$ & $\begin{array}{l}\text { HBIG } \\
\text { Booster dose of hepatitis } \\
\text { B vaccine } \\
\text { Repeat HBIG at } 1 \text { month }\end{array}$ & $\begin{array}{l}\text { HBIG } \\
\text { Consider booster dose } \\
\text { of hepatitis B vaccine } \\
\text { Repeat HBIG at } 1 \\
\text { month }\end{array}$ & $\begin{array}{l}\text { No HBIG } \\
\text { Consider booster } \\
\text { dose of hepatitis B } \\
\text { vaccine }\end{array}$ \\
\hline
\end{tabular}

hepatitis A and B vaccines is more immunogenic. Using higher strength $(40 \mu \mathrm{g})$ hepatitis $B$ vaccine as used in renal patients may also be worth trying in non-responders working in high risk settings. Non responders involved in a high-risk exposure should be given two doses of HBIG administered a month apart and a booster dose of hepatitis B vaccine would also be given. Ideally, the first dose of HBIG should be given within $48 \mathrm{~h}$ after exposure and no longer than 2 weeks after exposure.

\section{Management in Custody}

For staff or victims in contact with disease, it is wise to have a protocol in place for immediate management and risk evaluation. An example is shown in Fig. 10.1. While healthcare professionals are not expected to administer treatment, it is often helpful to inform persons concerned what to expect (Table 10.2).

Other measures to avoid an exposure include minimizing the risk of exposure by adopting the safe working practices outlined in the "Standard Precautions" section. There should be a protocol in place which explains how the person exposed should be managed and where they need to go to be assessed and treated where necessary. Any potential exposures should be dealt with as soon as possible. Detainees with disease can usually be managed in custody. If the detainee is bleeding, then the cell should be deemed out of action after they have left until it can be professionally cleaned. Contaminated bedding should be dealt with as described previously. If the detainee has chronic HBV and is on an antiviral agent (e.g. tenofovir), then the treatment course should be continued, if possible.

People who inject drugs should be encouraged to be vaccinated and to avoid sharing needles or any other drug paraphernalia (see "Management in Custody" in section "Other Bacteria Associated with Abscess Formation in People who Inject Drugs"). 


\section{Hepatitis C}

\section{Epidemiology and Prevalence}

Hepatitis C virus (HCV) is endemic in most parts of the world. In 2015 it was estimated that 71 million people are living with chronic hepatitis $\mathrm{C}$ infection. In that same year there were 1.75 million new infections world-wide [15]. As part of the WHO Global Health Sector Strategy the aim is to eliminate all viral hepatitis by 2030.

Seroprevalence studies carried out among blood donors have shown that the highest prevalence exists in Egypt-13\% in 2016. This has been ascribed to contaminated needles used in the treatment of schistosomiasis carried out between the 1950s and the 1980s [16].

Intermediate prevalence (1-5\%) exists in Eastern Europe, the Mediterranean, the Middle East, the Indian Sub-continent and parts of Africa and Asia. In Western Europe, most of Central America, Australia and limited regions in Africa including South Africa, the prevalence is low (0.2-0.5\%). Previously, America was included in the low prevalence group, but a report published in 2015 [17] indicated that up to 5.2 million Americans, i.e. 1.6\% of the population, have antibody to $\mathrm{HCV}$, representing either ongoing or previous infection. It also states that HCV accounts for approximately $15 \%$ of acute viral hepatitis in America.

Between $0.5-1 \%$ of the UK population are chronically infected with hepatitis C meaning that in 2018 there are 160,000 people living with chronic infection. However, within any country, there are certain groups that have a higher chance of carrying $\mathrm{HCV}$. In the UK the most important risk factor of hepatitis $\mathrm{C}$ is injecting drug use accounting for $90 \%$ of all lab reports where a risk factor was disclosed [18]. In $201654 \%$ of people who had injected psychoactive drugs and participated in the Unlinked Anonymous Monitoring Survey (UAMS) tested positive for antibodies to hepatitis C. However, only $52 \%$ of those surveyed were aware of their status impacting on the number of people who could seek treatment. The survey also revealed that $18 \%$ of participants still share needles but this is still a fall when compared with the $23 \%$ recorded in 2005 .

There has been a $3 \%$ fall in the number of deaths from HCV end stage liver disease and hepatocellular carcinoma between 2014 and 2016. This has been attributed to more patients seeking treatment and an improvement in the treatment.

\section{Symptoms and Complications}

After an incubation period of 6-8 weeks, the acute phase of the disease lasts approximately 2-3 years. Unlike hepatitis A (HAV) or HBV, the patient is usually asymptomatic; therefore, the disease is often missed unless the individual has reported a specific exposure and is being monitored. Other cases are found by chance, when raised liver enzymes are found on a routine blood test.

A "silent phase" follows the acute phase when the virus lies dormant and the liver enzymes are usually normal. This period lasts approximately 10-15 years. 
Reactivation may then occur. Subsequent viral replication damages the hepatocytes, and liver enzymes rise to moderate or high levels.

Antibodies develop 4-6 weeks after the acquisition of the virus, with $97 \%$ having detectable antibodies by 6 months. RNA can be detected by PCR 2-3 weeks after acquisition of the virus.

Eighty percent of individuals who are HCV antibody-positive are infectious, regardless of the levels of their liver enzymes. Approximately $80 \%$ of people develop chronic infection, one fifth of whom progress to cirrhosis. There is a much stronger association with hepatocellular carcinoma than with HBV. An estimated $1.25-2.5 \%$ of patients with HCV-related cirrhosis develop liver cancer [19]. Less than $2 \%$ of chronic cases resolve spontaneously.

\section{Routes of Transmission}

The main route of acquisition for hepatitis $\mathrm{C}$ is through injecting drug use, unsafe injection practice, and unscreened blood transfusions. Transmission through the sexual route is not common and only appears to be significant if there is repeated exposure with one or more people infected with HCV [18]. Mother-to-baby transmission is not common, but has been reported [20]. Theoretically, household spread is also possible through sharing contaminated toothbrushes or razors.

Since the disease is often silent, there is a need to raise awareness among the general population on how to avoid infection and to encourage high-risk groups to be tested. Healthcare professionals should also be educated to avoid occupationally acquired infection. An example of good practice is contained within the document 'Hepatitis C strategy for England', issued by the Department of Health in 2002 [19].

\section{Risks from Exposure from HCV RNA-Positive Person}

Blood or bloodstained body fluids need to be involved for a risk to occur. Saliva alone is not deemed to be a risk. The risk from a single needlestick incident is $1.8 \%$ (range $0-7 \%$ ). Contact through a contaminated cut is estimated at $1 \%$. For penetrating bite injuries, it is only considered a risk if blood is involved. Blood or bloodstained body fluids have to be involved in transmission through mucous membrane exposure. This may account for the lower than expected prevalence among the gay population.

\section{Management in Custody}

\section{Staff/Victims in Contact with Disease}

Follow the immediate management flow chart, making sure all available information is obtained. Inform the designated hospital and/or specialist as soon as possible. If the contact is known and is thought to be immunocompromised, and he or she has 
consented to provide a blood sample, it is important to tell the specialist, as their antibody tests may be spuriously negative. In this instance, a different test should be used (polymerase chain reaction [PCR] which detects viral RNA).

The staff member/victim will be asked to provide a baseline sample of blood ideally within $48 \mathrm{~h}$ of the exposure. Further samples may be taken at 4-6 weeks and again at 12 weeks. If tests are negative at 12 weeks, but the risk was deemed high, then follow-up may continue for up to 24 weeks. If any of the follow-up samples are positive, then the original baseline sample will be tested to ascertain whether the infection was acquired through the particular exposure.

Treatment of hepatitis $\mathrm{C}$ infection has been improved more recently with the use of Direct Acting Antiviral agents e.g. sofosbuvir. These drugs act by targeting nonstructural proteins of the virus which disrupts viral replication and infection. They can be given orally, for shorter durations and have an improved safety profile over the pegylated interferons used previously and can cure the infection within 2-3 months. Treatment is usually not started till after 6 months as between 15-45\% of people can spontaneously clear the virus in the acute phase. Prior to these drugs being developed Genotype 1 was notoriously difficult to treat. Now with a combination of drugs there is a cure rate of over $90 \%$. Recovery from hepatitis C does not confer immunity and it is possible to become infected again [21].

Co-infection with HIV also occurs and in 2015 worldwide there was around 2.3 million living with both HCV and HIV. In the UK data studied between 2008 and 2014 showed that around $4 \%$ of people with HCV were co infected with HIV. More than $84 \%$ of them were male, and $66 \%$ were of white ethnicity. Two thirds of those who were co-infected were diagnosed with HIV $\geq 6$ months before HCV [22].

Detainees with disease: Unless they are severely ill, detainees can be managed in custody. Special precautions are only required if they are bleeding. Custody staff should wear gloves if contact with blood is likely. Contaminated bedding should be handled appropriately and the cell cleaned professionally after use. Medication should be continued wherever possible.

\section{Hepatitis D (Delta Agent)}

This defective transmissible virus discovered in 1977 requires HBV for its own replication. At least 5\% of people with chronic hepatitis B are co-infected with HDV meaning that about 15-20 million people world-wide are infected. High prevalence areas include Central and West Africa, Central and Northern Asia, Vietnam, Mongolia, Pakistan, Japan and Chinese Taipei, the Pacific islands of Kiribati and Nauru, the Middle East, Eastern Europe, the Amazon Basin and Greenland. The number of cases has been falling since the 1980s with the introduction of a successful global hepatitis B immunization program [23].

HDV is associated with acute (co-infection) and chronic hepatitis (superinfection) and can exacerbate pre-existing liver damage caused by $\mathrm{HBV}$ in as little as 5 years. The routes of transmission and at-risk groups are the same as for HBV. Staff/ victims in contact with a putative exposure and detainees with disease should be 
managed as for HBV. Current guidelines advise treatment with pegylated Interferonalpha for 28 weeks, but this would not be practical to continue in the custodial setting $[23,24]$.

\section{Human Immunodeficiency Virus}

\section{Epidemiology and Prevalence}

HIV was first identified in 1983-2 years after the first reports were made to the CDC Atlanta, GA, of an increased incidence of two unusual diseases (Kaposi's sarcoma and Pneumocystis carinii pneumonia) occurring among the gay population in San Francisco. The scale of the virus gradually emerged over the years, and by the end of 2016, there was an estimated 36.7 million people throughout the world living with HIV or AIDS. Over $80 \%$ of the world total live in Africa and India [25].

By the end of 2015 the number of people living with HIV in the UK was estimated at 101,200 with around 13,500 (13\%) unware of their infection. The overall HIV prevalence in the UK is about $0.16 \%$ [26].

The number of new diagnoses has continued to fall over the past 10 years with a marked decrease in 2016 and 2017. From 2017 data the total number of new HIV diagnoses was 4363 with most among men who have sex with men (2330). This still represents a $30 \%$ drop since 2015 . Around 1400 new cases were diagnosed in heterosexual woman and around 1000 new cases in heterosexual men. PWIDs have remained consistently low with only 140 new diagnoses being made in 2017 [27]. This equates to about 1 in 100 PWID who are living with HIV. Most are accessing antiviral treatment but are more likely to be diagnosed late [8].

The proportion of people being diagnosed at a late stage of infection (CD4 count $<350$ cells $/ \mathrm{mm}^{3}$ at diagnosis) remains high at around $40 \%$. This is significant as when a diagnosis is made late there is a tenfold increased risk of death within a year of diagnosis and an increased risk of onward transmission. The highest risk group for late diagnosis was black African heterosexual men (69\%) and the lowest rates were among gay and bisexual men (33\%) [27].

UK data collected in 2017 showed that $98 \%$ of persons seen for HIV care are receiving anti-retroviral therapy (ART) compared with 79\% in 2008 (Table 10.4).

Table 10.4 Persons seen for HIV care in the UK by ethnicity and probable routes of exposure (2017)

\begin{tabular}{l|l|l|l|c}
\hline & MSM (\%) & Heterosexual (\%) & IDU (\%) & Mother to child (\%) \\
\hline White & 84 & 25.6 & 87.5 & 9.3 \\
\hline Black African & 1.7 & 56.9 & 2 & 70.9 \\
\hline Black Caribbean & 1.99 & 4.06 & 3.3 & 1.6 \\
\hline Asian & 3.6 & 3.8 & 1.8 & 4.3 \\
\hline
\end{tabular}

Taken from National HIV surveillance data tables [28] 


\section{Window Period for HIV}

Following infection with HIV there is a period of time when the person is very infectious but an HIV antibody test could be negative. This is known as the window period, which for a fourth generation antigen/antibody test is about 4 weeks. At this time about $95 \%$ of patients will test positive. By 12 weeks the figure is $99.9 \%$. The earliest point where antibodies could be detected is 2 weeks.

PCR can be used to measure the viral load and this can be detected as early as 7 days after infection. The higher the viral load the more likely the person will have seroconversion symptoms. At the same time as the viral load becomes detectable the p24 viral antigen is also present in the blood. A negative p24 and viral load early on in infection do not mean that the person has not got HIV. Usually an antibody test is conducted 4 weeks after exposure and if it is negative it is repeated at 12 weeks.

During the acute phase of the infection, between $50-80 \%$ of people experience a sero-conversion "flu-like" illness. In some people the symptoms are so mild that they may be missed and in $20 \%$ they get nothing at all. The individual is infectious at this time, as viral antigen (p24) and viral particles are present in the blood. As antibodies start to form, the virus disappears and the individual enters the latent phase. They are non-infectious and remain well for a variable period of time (7-15 years). Development of the AIDS marks the terminal phase of disease. Viral antigen re-emerges and the individual is once again infectious. With the development of effective ART patients who take a combination of drugs are very unlikely to develop AIDS. Treatment has changed HIV from being a fatal disease to being a chronic and very manageable condition.

\section{Routes of Transmission}

Parenteral transmission includes needle stick injuries, bites, unscreened blood transfusions, tattooing, acupuncture and dental procedures where equipment is inadequately sterilised. Risk of transmission is increased with deep penetrating injuries with hollow bore needles that are visibly bloodstained, especially when the device has previously been in the source patient's (contact) artery or vein. Other routes include mucous membrane exposure, (eyes, mouth and genital mucous membranes) and contamination of broken skin.

The higher the viral load in the contact, the greater the risk of transmission. This is more likely at the terminal stage of infection unless the patient is being treated. HIV is transmitted mainly through blood or other body fluids that are visibly bloodstained with the exception of semen, vaginal fluid and breast milk. Saliva alone is most unlikely to transmit infection. Therefore, people who have sustained penetrating bite injuries can be reassured that they are not at risk providing the contact was not bleeding from the mouth at the time. 


\section{Risk of Seroconversion}

The risk from a single percutaneous exposure from a hollow bore needle is low $(<3$ in 1000) and a single mucocutaneous exposure is even less likely to result in infection $(<1$ in 1000).

The risk from sexual exposure varies, though it appears that there is a greater risk with receptive anal intercourse compared with receptive vaginal intercourse [29, 30] (see Table 10.5).

\section{Body Fluids Containing HIV}

High-risk fluids include blood, semen, vaginal fluid and breast milk. There is little or no risk from saliva, urine, vomit or faeces unless they are visibly bloodstained. Other fluids that constitute a theoretical risk include CSF, peritoneal, pleural, synovial or pericardial fluid.

\section{Management in Custody of Staff/Victims in Contact with Disease}

Management in custody of staff/victims in contact with disease includes following the immediate management flow chart (Fig. 10.1) and contacting the designated hospital/specialist with details of the exposure. Where possible, obtain a blood sample from the contact. Like HBV and HCV, blood samples taken for HIV testing can only be taken with informed consent in the United Kingdom. There is no need to go into details about the meaning of the test, but the contact should be encouraged to attend the genito-urinary department (or similar) of the designated hospital to discuss the test results. Should the contact refuse to provide a blood sample, then any

Table 10.5 Risks of HIV transmission from a known HIV positive individual

\begin{tabular}{l|l}
\hline Type of exposure & Estimated risk of HIV transmission ${ }^{\mathrm{a}}$ \\
\hline Blood transfusion (one unit) & Per exposure $(\%)$ \\
\hline Sharing injection equipment & $90-100$ \\
\hline Needle stick injury & 0.63 \\
\hline Human bite & 0.3 \\
\hline Receptive anal intercourse & $<0.001$ \\
\hline Receptive vaginal intercourse & 0.138 \\
\hline Insertive anal intercourse & $0.08 \%$ \\
\hline Insertive penile vaginal intercourse & $0.06-0.11$ \\
\hline Receptive oral sex (fellatio) & $0.03-0.09$ \\
\hline
\end{tabular}

Adapted from the BASHH guidelines [30]

aThis assumes that the HIV positive person has a detectable viral load and is not on ART 
Table 10.6 PEP management following a potential HIV exposure

\begin{tabular}{|c|c|c|c|c|}
\hline & & HIV status & & \\
\hline & HIV positive & & $\begin{array}{l}\text { Unknown } \\
\text { HIV status }\end{array}$ & \\
\hline & $\begin{array}{l}\text { HIV VL } \\
\text { unknown/ }\end{array}$ & $\begin{array}{l}\text { HIV VL } \\
\text { undetectable }\end{array}$ & $\begin{array}{l}\text { From high } \\
\text { prevalence }\end{array}$ & $\begin{array}{l}\text { From low } \\
\text { prevalence }\end{array}$ \\
\hline & $>200$ copies $/ \mathrm{mL}$ & $<200$ copies/mL & $\begin{array}{l}\text { Country or } \\
\text { risk group }\end{array}$ & $\begin{array}{l}\text { Country or } \\
\text { risk group }\end{array}$ \\
\hline & For $>6$ months & & & \\
\hline Receptive anal sex & $\mathrm{R}$ & NR & $\mathrm{R}$ & NR \\
\hline Insertive anal sex & $\mathrm{R}$ & NR & Consider & NR \\
\hline Receptive vaginal sex & $\mathrm{R}$ & NR & Consider & NR \\
\hline Insertive vaginal sex & Consider & NR & Consider & NR \\
\hline $\begin{array}{l}\text { Fellatio with or without } \\
\text { ejacualtion }\end{array}$ & NR & NR & NR & NR \\
\hline Splash of semen in eye & NR & NR & NR & NR \\
\hline $\begin{array}{l}\text { Sharing of injection } \\
\text { equipment }\end{array}$ & $\mathrm{R}$ & NR & Consider & NR \\
\hline Human bite & NR & NR & NR & NR \\
\hline $\begin{array}{l}\text { Needlestick from a discarded } \\
\text { needle in the community }\end{array}$ & & & NR & NR \\
\hline Occupational needlestick & $\mathrm{R}$ & NR & Consider & NR \\
\hline
\end{tabular}

$R$ recommended, $N R$ not recommended

information about their lifestyle, ethnic origin, state of health, etc. may be useful for the specialist to decide whether post-exposure prophylaxis (PEP) should be given to the recipient. Where saliva only is involved in a penetrating bite injury, there is every justification to reassure the recipient that there is little risk of acquiring HIV. However, it is still wise to take advice from a specialist. Table 10.6 shows the various exposures and whether post exposure prophylaxis (PEP) would be recommended.

In the UK, the current recommended regime for PEP is one Truvada tablet ( $254 \mathrm{mg}$ tenofovir and $200 \mathrm{mg}$ emtricitabine) once a day plus raltegravir twice a day for 28 days [30].

Treatment should be started as soon as possible after exposure and ideally within $24 \mathrm{~h}$, but it can be considered for up to $72 \mathrm{~h}$. It is usually given for 4 weeks unless the contact is subsequently identified as HIV negative or the recipient develops tolerance or toxicity occurs.

In the UK high risk countries or groups would include men who have sex with men (MSM) and PWID from high risk countries e.g. Eastern Europe, and Central Asia. It would also include individuals who have immigrated to the UK from high risk countries particularly sub Saharan Africa.

If the source states that they are HIV positive, and are being treated, then it is important to establish what the viral load, resistance profile and treatment history is. For the recipient not to need PEP, if the viral load of the source is reported as undetectable it has to have been less than 200 copies $/ \mathrm{mL}$ for at least 6 months. Where 
there is any uncertainty about the results or doubt as to compliance with ART then PEP should be given after unprotected anal intercourse. Routine blood test monitoring is not recommended for raltegravir based PEP if baseline bloods are normal and there is no clinical indication.

Other useful information that may influence the decision whether to treat with the standard regime or use alternative drugs include interaction with other medications that the recipient may be taking or if the contact has been on anti-retroviral therapy which has not been sustained or drug resistance is suspected.

PEP is not considered for exposure to low or no risk fluids through any route, nor where the source is unknown, e.g. a discarded needle. Despite the appropriate use and timing of PEP, there have been reports of failure [31, 32].

\section{Management in Custody of Detainees with HIV}

Unless they are severely ill, they can be kept in custody. Every effort should be made to continue any treatment they may be receiving. Apply standard precautions when dealing with the detainee and ensure that contaminated cells and/or bedding are managed appropriately.

\section{Transmission Through Contact with Lesions or Organisms}

\section{Varicella (Chicken Pox)}

\section{Epidemiology and Prevalence}

Cases of this highly infectious disease occur throughout the year, but are more frequent in winter and early spring. This seasonal endemicity appears to be blurring with global warming but in the UK it reaches a peak between March and May. In the UK, the highest prevalence occurs in the 4-10 years age group. Ninety percent of the population over the age of 40 are immune [33]. A similar prevalence has been reported in other parts of Western Europe and the USA. In South East Asia, Varicella is mainly a disease of adulthood [34]. Therefore, people born in these countries who have moved to the UK are more likely to be susceptible to chicken pox.

There is a strong correlation between a history of chicken pox and serologic immunity (97-99\%). Most adults born and living in industrialised countries with an uncertain or negative history of chicken pox are also seropositive (70-90\%). In March 1995, a live-attenuated vaccine was licensed for use in the USA and a policy for vaccinating children and susceptible healthcare personnel was introduced. In the summer of 2002 in the UK, GlaxoSmithKline launched a live-attenuated vaccine called Varilrix. In December 2003, the Department of Health, following advice from the Joint Committee on Vaccination and Immunisation (JCVI), recommended that the vaccine be given for non-immune healthcare workers who are likely to have direct contact with individuals with chicken pox. Any healthcare worker with no previous history of chicken pox should be screened for immunity, and if no 
antibodies are found, they should receive two doses of vaccine 4-8 weeks apart. The other group of people who would be considered for vaccination are close contacts (e.g. family members) of patients with weakened immune systems who would be at high risk of developing complications.

The vaccine is still not currently recommended for children in the UK and should not be given during pregnancy. The rationale behind not vaccinating in the UK stems from the concern that if children are vaccinated then the virus is not circulating. This means that children who have not been vaccinated will be more susceptible as adults when the disease can be more serious or in pregnancy when the baby can be harmed. As adults, being exposed to natural disease from infected children boosts immunity and protects the adults from developing shingles. Therefore it is likely that the number of cases of shingles would rise if children were routinely vaccinated. Other countries, including the USA and Australia, disagree with this policy and vaccinate their children.

\section{Incubation Period and Symptoms}

Following an incubation period of 7-21 days (this may be shorter in the immunocompromised), there is usually a prodromal "flu-like" illness which lasts 1-2 days before the onset of the rash. This coryzal phase may be absent particularly in young children. The lesions typically appear in crops; rapidly progressing from red papules through vesicles to open sores that crust over and separate by 10 days. They appear on the face and scalp and spread on to the trunk and then the limbs. The distribution of the rash is centripetal, i.e. more over the trunk and face than on the limbs which is the converse of small pox. In adults, the disease is often more severe with lesions involving the scalp and mucous membranes of the oropharynx.

\section{Complications}

In children, the disease is often mild, unless they are immunocompromised, so are unlikely to experience complications. In adults (defined as 15 years or older), the picture is rather different [35]. Secondary bacterial infection is common, but rarely serious. There is an increased likelihood of permanent scarring. Hemorrhagic chickenpox typically occurs on the 2nd or 3rd day of the rash. Usually, this is limited to bleeding into the skin, but life-threatening melaena, epistaxis or hematuria can occur.

Varicella pneumonia ranges from patchy lung consolidation to overt pneumonitis and occurs in 1 in 400 cases [36]. It can occur in previously healthy individuals (particularly adults), but the risk is increased in those who smoke. Immunocompromised people are at the greatest risk of developing this complication. It runs a fulminating course and is the commonest cause of Varicella-associated death.

Fibrosis and permanent respiratory impairment may occur in those who survive. Any suspicion of lung involvement is an indication for immediate treatment and any detainee or staff member should be sent to hospital. Involvement of the CNS includes a variety of conditions including meningitis, Guillain-Barre and encephalitis. The latter is more common in the immunocompromised and can be fatal.

Complications can also occur in pregnancy—see At-risk groups. 


\section{Period of Infectivity}

This is taken as 1-3 days before the first lesions appear to the end of new vesicle formation and the last vesicle has crusted over. This typically is 5-7 days after onset, but may last up to 14 days. It is more likely to be prolonged in immunocompromised people.

\section{Routes of Transmission}

The primary route is through direct contact with open lesions of chicken pox. However, it is also spread through aerosol or droplets from the respiratory tract. Chicken pox may also be acquired through contact with open lesions of shingles (Varicella zoster), but this is less likely as shingles is less infectious than chicken pox. The secondary infection rate from a household contact with chicken pox can be as high as $90 \%$.

\section{At-Risk Groups}

Non-immune individuals are at risk of acquiring disease. Approximately $10 \%$ of the adult population born in the UK and $<5 \%$ of adults in the USA fall into this category. Therefore, it is more likely that if chicken pox is encountered in the custodial setting, it will involve people born outside the UK (in particular South East Asia) or individuals who are immunocompromised and have lost immunity. Non-immune pregnant women are at risk of developing complications.

Pneumonia can occur in up to $10 \%$ of pregnant women with chicken pox and the severity appears to be increased in later gestation [37]. They can also transmit infection to the unborn baby [38]. If infection is acquired in the first 20 weeks, there is $<3 \%$ chance of it leading to congenital Varicella syndrome. This includes limb hypoplasia, microcephaly, cataracts and growth retardation. Mortality estimates are between $1-2 \%$.

Infection in the last trimester can lead to neonatal Varicella unless more than 7 days elapse between onset of maternal rash and delivery when antibodies have time to cross the placenta leading to either mild or inapparent infection in the newborn. In this situation, Varicella immunoglobulin (VZIG) should be administered to the baby as soon as possible after birth [39].

\section{Management in Custody}

Staff with chicken pox should stay off work until the end of the infective period (approximately 7-14 days). Those in contact with disease who are known to be nonimmune or who have no history of disease should contact the designated occupational health physician. A significant contact would be considered as being in the same room for at least $15 \mathrm{~min}$.

Detainees with visible disease should not be kept in custody if at all possible (especially pregnant women). If this is unavoidable, then non-immune or immunocompromised staff should avoid entering the cell or having close contact with the detainee.

Non-immune immunocompromised or pregnant individuals exposed to chickenpox should seek expert medical advice for the administration of VZIG. Aciclovir (or 
similar antiviral agent) should be given as soon as possible to immunocompromised people with chicken pox. It should also be considered for anyone over 15 years old who is non immune as they are more likely to develop complications. Immunosuppressed patients who have detectable varicella antibodies will not need VZIG. Second attacks of chicken pox can occur in such people but this is most likely to be due to a fault in cell-mediated immunity.

Do not give ibuprofen as this can cause serious skin infections. Do not give aspirin to under 16 year olds with chicken pox as this can lead to Reyes syndrome which is a serious condition that causes swelling to the liver and the brain. Anyone suspected of severe complications should be sent straight to hospital.

\section{Herpes Zoster (Shingles)}

\section{Epidemiology}

After chicken pox, the varicella zoster virus lies dormant in the dorsal root or cranial nerve ganglia, but may reactivate and re-emerge typically involving one dermatome [40]. The site of involvement depends on the sensory ganglion initially involved. Shingles is more common over the age of 50, but it can occur in children and is very common in the immunosuppressed at any age. The latter are also more susceptible to secondary attacks and involvement of more than one dermatome. Bilateral zoster is even rarer, but is not associated with a higher mortality.

In the UK, there is an estimated incidence of 1.2-3.4 per 1000-person years [41].

\section{Symptoms}

There may be a prodromal period of paresthesia and burning or shooting pains in the involved segment. This is usually followed by the appearance of a band of vesicles. Rarely, the vesicles fail to appear and only pain is experienced. This is known as zoster sine herpete. In individuals who are immunocompromised, disease may be prolonged and dissemination may occur but is rarely fatal. The overall fatality rate is estimated as $1 / 1000$ persons over 70 years old.

Shingles in pregnancy is usually mild. The fetus is only affected if viremia occurs before maternal antibody has had time to cross the placenta.

\section{Complications}

The most common complication of shingles is post-herpetic neuralgia (PHN) occurring in about $10 \%$ of cases. It is defined as pain lasting more than 120 days from rash onset [42]. It is more frequent in people over 50 and can lead to depression as the pain can be very debilitating and is mostly unresponsive to standard pain killers. Other drugs such as pregabalin and amitryptiline may help to alleviate symptoms. Infection of the brain can lead to encephalitis, involvement of motor neurones leading to ptosis, paralysis of the hand, facial palsy or contralateral hemiparesis. Involvement of the oculomotor division of the trigeminal ganglion can cause serious eye problems including corneal scarring. 


\section{Period of Infectivity}

Shingles is far less infectious than chicken pox and is only considered to be infectious up to 3 days after lesions appear.

\section{Routes of Transmission}

Shingles is only infectious following prolonged contact with lesions. Unlike chickenpox, airborne transmission is not a risk.

\section{At-Risk Groups}

Individuals who are immunocompromised may reactivate the dormant virus and develop shingles. People who have not had primary Varicella are at risk of developing chicken pox following prolonged direct contact with shingles.

Despite popular belief, it is untrue that immunocompetent people who have had chicken pox develop shingles when in contact with either chicken pox or shingles. Such occurrences are merely coincidental unless immunity is lowered.

\section{Management in Custody}

Staff with shingles should stay off work until the lesions are healed unless they can be covered. Staff who have had chicken pox are immune (including pregnant women) and are therefore not at risk. If they are non-immune (usually accepted as those without a history of chickenpox), they should avoid prolonged contact with detainees with shingles. Pregnant non-immune women should avoid contact altogether.

Detainees with disease may be kept in custody and any exposed lesions should be covered. It is well documented that prompt treatment attenuates the severity of the disease, reduces the duration of viral shedding, hastens lesion healing, and reduces the severity and duration of pain. It also reduces the likelihood of developing post-herpetic neuralgia [43]. Prompt treatment with Famciclovir (500 mg tds for 7 days, for example) or acyclovir ( $800 \mathrm{mg}$ five times a day for 7 days) should be initiated if the onset is 3 days or less. It should also be considered after this time if the detainee is over 50. Pregnant detainees with shingles can be reassured that there is minimal risk for both the mother and the unborn child. Expert advice should be sort before initiating treatment for the mother.

In the UK Zostavax (a live vaccine for shingles) was introduced in September 2013 as a single dose of vaccine for adults aged 70 on 1st September 2013 and aged 79 in the first year as part of a phased catch up. Data from the first 3 years of the program show that there has been a significant reduction in the number of cases of shingles and PHN despite the fact that the vaccine is only about $50 \%$ effective [44].

Shingrix is an inactivated shingles vaccine that has been introduced in the USA. This vaccine is given as a two dose course and is reported as being over $90 \%$ effective. The uptake has been so great that there have been vaccine shortages while the manufacturers catch up with the unprecedented demand. It has yet to be introduced into the UK. 


\section{Scabies}

\section{Epidemiology}

This tiny parasitic mite (Sarcoptes scabiei) has infested humans for over 2500 years. Experts estimate that in excess of 300 million cases occur worldwide each year. The female mite burrows into the skin especially around the hands, feet and male genitalia, in about $2.5 \mathrm{~min}$. Eggs are laid and hatch into larvae that travel to the skin surface as newly developed mites.

\section{Symptoms}

The mite causes intense itching which is often worse at night and is aggravated by heat and moisture. The irritation spreads outside the original point of infection due to an allergic reaction to mite feces. This irritation may persist for about 2 weeks after treatment, but can be alleviated by antihistamines.

Crusted scabies is a far more severe form of the disease. Large areas of the body may be involved. The crusts hide thousands of live mites and eggs making them difficult to treat. This so-called Norwegian scabies is more common in the elderly or the immunocompromised, especially those with untreated HIV.

\section{Incubation Period}

Following a primary exposure, it takes about 2-6 weeks before the onset of itching. However, further exposures reduce the incubation time to around 1-4 days.

\section{Period of Infectivity}

Without treatment, this is assumed to be indefinite. With treatment, the person should be considered infectious until the mites and eggs are destroyed-usually 7-10 days. Crusted scabies is highly infectious.

\section{Management in Custody}

Since transmission is through direct skin-to-skin contact with an infected case, gloves should be worn when dealing with individuals suspected of infestation. Usually prolonged contact is needed, unless the person has crusted Scabies where transmission occurs more easily. The risk of transmission is much greater in households where repeated or prolonged contact is likely.

Since mites can survive in bedding of clothing for up to $24 \mathrm{~h}$, gloves should also be worn when handling these items. Bedding should be treated by washing at a temperature of at least $50{ }^{\circ} \mathrm{C}$. Professional cleaning of the cell is only warranted in cases of crusted scabies.

\section{Treatment}

The preferred treatment for scabies is either Permethrin cream (5\%) or aqueous Malathion $(0.5 \%)$ [45]. Either treatment has to be applied to the whole body and should be left on for at least $8 \mathrm{~h}$ in the case of permethrin and $24 \mathrm{~h}$ for Malathion before washing off. Lindane is no longer considered the treatment of choice, as there may be complications in pregnancy [46].

Treatment in custody may not be practical, but should be considered when the detainee is thought to have Norwegian scabies. 


\section{Head Lice}

\section{General Information}

Like scabies, head lice occur worldwide and are found in the hair close to the scalp. The eggs or nits cling to the hair and are difficult to remove, but are not harmful. If you see nits then you can be sure that lice are also present. The latter are best seen when the hair is wet. The lice bite the scalp and suck blood causing intense irritation and itching.

\section{Route of Transmission}

They can only be passed from direct hair to hair contact.

\section{Management in Custody}

It is only necessary to wear gloves when examining the head for whatever reason. The cell does not need to be cleaned after use, since the lice live on or near skin. Bedding may be contaminated with shed skin so should be handled with gloves and laundered or incinerated.

The presence of live lice is an indication for treatment either by physical removal with a comb or the application of an insecticide. The latter may be more practical in custody. $0.5 \%$ aqueous Malathion should be applied to dry hair and washed off after $12 \mathrm{~h}$. The hair should then be shampooed as normal.

\section{Crabs or Body Lice}

\section{General Information}

They are more commonly found in the pubic, axillary, chest and leg hair. However, eyelashes and eyebrows may also be involved. They are associated with people who do not bath or change clothes regularly. The person usually complains of intense itching or irritation.

\section{Routes of Transmission}

The main route is from person to person by direct contact, but eggs can stick to fibers so clothing and bedding should be handled with care (see section below).

\section{Management in Custody}

Staff should always wear gloves if they are likely to come into contact with any hirsute body part. Clothing or bedding should be handled with gloves and either laundered or incinerated.

Treatment of a detainee in custody is good in theory but probably impractical as the whole body has to be treated.

\section{Fleas}

\section{General Information}

Fleas lay eggs on floors, carpets and bedding. In the UK, most fleabites come from cats or dogs. The eggs and larvae fleas can survive for months and are reactivated in 
response to animal or human activity. Since animal fleas jump off humans after biting, most detainees with fleabites will not have fleas, unless they are human fleas.

\section{Management in Custody}

Treatment is only necessary if fleas are seen. After use, the cell should be vacuumed and cleaned with a proprietary insecticide. Any bedding should be removed wearing gloves, bagged and either laundered or incinerated.

\section{Bedbugs}

\section{General Information}

Bedbugs live and lay eggs on walls, floors, furniture and bedding. If you look carefully, fecal tracks may be seen on hard surfaces. If they are present for long enough, then they emit a distinct odor. Bedbugs are rarely found on the person, but may be brought in on clothing or other personal effects.

\section{Symptoms}

Bedbugs bite at night and can cause sleep disturbance.

\section{Management in Custody}

The detainee does not need to be treated, but the cell should be deemed out of use until it can be vacuumed and professionally cleaned with an insecticide solution. Any bedding or clothing should be handled with gloves and disposed of as appropriate.

\section{Methicillin-Resistant Staphylococcus aureus}

\section{Epidemiology}

Staphylococcus aureus is commonly carried on the skin or in the nose of healthy people. Approximately $25-30 \%$ of the population is colonized with the bacteria, but remain well [47]. From time to time, the bacteria cause minor skin infections that usually do not require antibiotic treatment. However, more serious problems can occur, e.g. infection of surgical wounds, drug injection sites, osteomyelitis, pneumonia or bacteremia. Over the last 50 years, the bacteria have become increasingly resistant to penicillin-based antibiotics [48] and in the last 20 years to an increasing number of alternative antibiotics. These multi-resistant bacteria are known as methicillin-resistant $S$. aureus (MRSA).

MRSA is prevalent worldwide. Like non-resistant staphylococci, it may remain undetected as a reservoir in colonized individuals, but can also produce clinical disease. It is more common among the elderly, debilitated or immunocompromised people or those with open wounds. Clusters of skin infections with MRSA have been reported among injecting drug users since 1981 in America [49, 50] and more recently similar strains have been found in the UK in PWIDs in the community [51]. This may have particular relevance for the healthcare professional when dealing 
with injecting drug users' ulcers or abscesses. Immunocompetent people rarely get MRSA and should not be considered at risk. Between April 2003 and December 2008, there were 74 recorded cases of a community-acquired MRSA in injecting drug users in England and Wales [52]. A study conducted from the CDC in Atlanta looked at data from injecting drug users between 2005 and 2016. The data showed that PWID are $16.3 \times$ more likely to develop invasive MRSA infections than others.

Data from 2016 in the UK from the mandatory enhanced surveillance showed that $13 \%$ of the Methiciliin Sensitive Staphylcoccus Aureus (MSSA) bacteremia and $8.1 \%$ of the MRSA bacteremias were associated with injecting drug use [53]. This has increased since 2011 from 6.9\% for MSSA and 1.6\% for MRSA.

In 2014 in Bristol there was an increase in the number of severe MRSA infections among PWID. A study showed that $8.7 \%$ of PWID in Bristol were carriers compared with $1-4 \%$ for the UK population in general. The rise in cases was thought to be due to a specific clone and to the increase in injecting outside and into the groin [53].

\section{Route of Transmission}

The bacteria are usually spread via the hands of staff after contact with colonized or infected detainees or devices, items (e.g. bedding, towels, soiled dressings) or environmental surfaces that have been contaminated with MRSA-containing body fluids.

\section{Management in Custody}

With either known or suspected cases (consider all abscesses/ulcers of injecting drug users as infectious), standard precautions should be applied. Staff should wear gloves when touching mucous membranes, non-intact skin, blood or other body fluids or any items that could be contaminated. They should also be encouraged to wash hands with an antimicrobial agent whether or not gloves have been worn. After use, gloves should be disposed of in a yellow "hazard" bag and not allowed to touch surfaces. Masks and gowns should only be worn when carrying out procedures that generate aerosols of blood or other body fluids. Since this is an unlikely scenario in the custodial setting, they should not be necessary. Gloves should be worn when handling bedding or clothing and all items should be disposed of in the appropriate manner. Any open wounds should be covered as soon as possible. The cell should be cleaned professionally after use if there is any risk that it has been contaminated.

\section{Other Bacteria Associated with Abscess Formation in Injecting Drug Users}

\section{Epidemiology}

Over the last decade, there has been an increasing awareness of the bacterial flora colonizing injection sites that may potentially lead to life-threatening infection [54]. 
In 1997, a sudden increase in needle abscesses caused by a clonal strain of Group A Streptococcus (GAS) was reported among hospitalized intravenous drug users (IDUs) in Berne, Switzerland [55]. A recent study in the UK showed that the predominant isolate is $S$. aureus, with Streptococcus species forming just under one fifth (50\% beta-hemolytic streptococci) [56].

There have also been reports of both non-sporing and sporing anaerobes (e.g. Bacteroides and Clostridia species including Clostridium botulinum) [57, 58]. In terms of numbers, in 2003-2004, injecting drug use was one of the most important risk factors for Group A streptococcal infection in the United Kingdom accounting for 20\%. Over subsequent years the number of cases fell [52]. However, in 2016/17 there has been an increase in invasive Group A Streptococcal infections (iGAS) amongst homeless people and PWID in England and Wales. In Brighton, Gloucestershire, Bristol and London there was an emm66 cluster and more recently an emm99 cluster in Bournemouth which is spreading more widely [53].

In 2000, laboratories in Glasgow were reporting isolates of $C$. novyi among IDUs with "serious unexplained illness". By 12 June 2000, a total of 42 cases (18 definite and 24 probable) had been reported. A definite case was defined as an IDU with both severe local and systemic inflammatory reactions. A probable case was defined as an IDU who presented to hospital with an abscess or other significant inflammation at an injecting site and had either a severe inflammatory process at or around an injection site or a severe systemic reaction with multiorgan failure and a high white cell count [59].

In the UK, the presence of $C$. botulinum in infected injection sites is a relatively new phenomenon. Up to the end of 1999 , there were no cases reported to the Public Health Laboratory Service (PHLS). Since then the number has increased with a total of 13 cases in the UK and Eire being reported since the beginning of 2002. It is thought that these cases are associated with contaminated batches of heroin. Simultaneous injection of cocaine increases the risk by encouraging anaerobic conditions. Anaerobic flora in wounds may have serious consequences for the detainee but the risk of transmission to staff is virtually non-existent. By the end of 2008, a cumulative total of 132 suspected cases had been reported from the United Kingdom, with 86\% of cases occurring in England. Four cases were reported in 2008 alone [52]. In 2016 wound botulism still continues to be a problem albeit rare with seven cases being reported and one case of confirmed tetanus [8].

In December 2009, two injecting drug users in Scotland died from anthrax contaminated heroin. Following this, two further deaths occurred in England in February 2010. An alert was issued first by the Department of Health and then, by the National Treatment Agency warning any drug user of the possible risks. Spores from the bacillus anthracis can contaminate heroin without any obvious signs. Anthrax can be acquired by injecting, smoking or inhaling heroin. Obvious symptoms include excessive swelling and redness at injection sites, fever, headache or shortness of breath when the heroin is smoked. Users are advised to go straight to the Emergency Department if they are at all worried. Such infections with spore forming bacteria 
will always occur from time to time. Healthcare professionals should be mindful at all times. There were no reported cases of anthrax in 2016.

\section{Management in Custody}

Staff should be reminded to wear gloves when coming into contact with detainees with infected skin sites exuding pus or serum and that any old dressings found in the cell should be disposed of into the yellow bag marked "clinical waste" in the medical room. Likewise, any bedding should be bagged and laundered or incinerated after use. The cell should be deemed out of use and professionally cleaned after the detainee has gone.

The healthcare professional managing the detainee should clean and dress open wounds as soon as possible to prevent the spread of infection. It may also be appropriate to start a course of antibiotics if there is abscess formation, signs of cellulitis and/or the detainee is systemically unwell. However, infections can often be lowgrade because the skin, venous and lymphatic systems have been damaged by repeated penetration of the skin. In these cases, signs include lymphoedema, swollen lymph glands and darkly pigmented skin over the area. Fever may or may not be present, but septicemia is uncommon unless the individual is immunocompromised (e.g. HIV positive). Co-Amoxiclav is the preferred treatment of choice as this covers majority of staphylococci, streptococci and anaerobes (the dose used is dependent on the degree of infection).

Necrotizing fasciitis and septic thrombophlebitis are rare but life-threatening complications of intravenous drug use. Any detainee suspected of either of these needs hospital treatment. Advice about harm reduction should also be given. This includes encouraging drug users to smoke rather than inject or at least to advise them to avoid injecting into muscle or skin. Although most injecting drug users are aware of the risk of sharing needles, they may not realize that sharing any drug paraphernalia could be hazardous. Advice should be given to use the minimum amount of citric acid to dissolve the heroin as the acid can damage the tissue under the skin allowing bacteria to flourish. Drugs should be injected at different sites using fresh works for each injection. This is particularly important when "snowballing" as crack cocaine creates an anaerobic environment. Medical help should be requested if any injection site become painful and swollen or shows signs of pus collecting under the skin. Much work has been done to vaccinate PWID against hepatitis B but there is always an opportunity to check their status and encourage them to get vaccinated if they have not had it. Hepatitis A vaccine should also be encouraged as cases of the disease do get reported in PWID.

Another serious but relatively rare problem is the risk from broken needles in veins. Embolization can take anything from hours to days or even longer if it is not removed. Complications may include endocarditis, pericarditis or pulmonary abscesses [60, 61]. PWID should be advised to seek medical help as soon as possible, and should such a case present in custody, then the detainee should be sent straight to hospital. 


\section{Management of Human and Dog Bites}

The HCP may encounter bites in four circumstances:

1. During the examination of victims of assault (both children and adults) where presentation is more likely to be late

2. Among police officers bitten during the arrest of a detainee

3. In detainees during the arrest if dogs have been used

4. Where detainees have been involved in a fight either around the time of arrest or earlier

A detailed forensic examination of bites is given in Chap. 4. With any bite that has penetrated the skin, the goals of therapy are to minimize soft tissue deformity and to prevent or treat infection.

\section{Epidemiology}

In the UK and USA, dog bites represent approximately three-quarters of all bites presenting to Emergency departments [62]. A single dog bite can produce up to $220 \mathrm{psi}$ of crush force in addition to the torsional forces as the dog shakes its head. This can result in massive tissue damage. Human bites may cause classical bite marks or puncture wounds (e.g. impact of fists on teeth) resulting in crush injuries.

\section{Rates and Risks of Infection}

An estimated $10-30 \%$ of dog bites and $9-50 \%$ of human bites lead to infection. Compare this with an estimated 1-12\% of non-bite wounds managed in Emergency Departments.

The risk of infection is increased with puncture wounds, hand injuries, full thickness wounds, wounds requiring debridement, and those involving joints, tendons, ligaments or fractures.

Co-morbid medical conditions such as diabetes, asplenia, chronic edema of the area, liver dysfunction, the presence of a prosthetic valve or joint, and an immunocompromised state may also increase the risk of infection.

\section{Other Complications of Bites}

Infection may spread beyond the initial site, leading to septic arthritis, osteomyelitis, endocarditis, peritonitis, septicemia and meningitis. Inflammation of the tendons or synovial lining of joints may also occur. If enough force is used, bones may be fractured or the wounds may be permanently disfiguring.

\section{Initial Management}

Encourage the wound to bleed unless it is already bleeding and irrigate with warm running water. Assessment as to whether hospital treatment is necessary should be made as soon as possible. Always refer if the wound is bleeding heavily or fails to stop when pressure is applied. Penetrating bites involving arteries, nerves, muscles, tendons, the hands or feet or resulting in a moderate-to-serious facial wound, or crush injuries also require immediate referral. 
If management within custody is appropriate, then ask about current tetanus vaccine status, HBV vaccination status and known allergies to antibiotics.

A full forensic documentation of the bite should be made as detailed in Chap. 4.

Note if there are clinical signs of infection such as erythema, edema, cellulitis, purulent discharge, or regional lymphadenopathy. Cover the wound with a sterile, non-adhesive dressing. Wound closure is rarely advised in primary care and is not generally recommended as data suggest that this may increase the risk of infection. This is particularly relevant for non-facial wounds, deep puncture wounds, bites to the hand, clinically infected wounds, and those occurring more than 6-12 h before presentation. Head and neck wounds in cosmetically important areas may be closed if less than $12 \mathrm{~h}$ old and not obviously infected. This should only be done in a tertiary setting by an appropriately trained health care professional.

\section{Pathogens Involved}

1. Bacteria

- Dog bites-Pasteurella canis, P. multocida, S. aureus, other staphylococci, Streptococcus species, Eikenella corrodens, Corynebacterium species and anaerobes including Bacteroides fragilis and $C$. tetani.

- Human bites-Streptococcus species, S. aureus, E. corrodens, and anaerobes including Bacteroides (often penicillin resistant), peptostreptococci species, and $C$. tetani. TB and syphilis may also be transmitted.

2. Viruses

- Dog bites-Outside of the UK, Australia and New Zealand, rabies should be considered. In the USA, domestic dogs are mostly vaccinated against rabies [63], and police dogs have to be vaccinated, so the most common source is from racoons, skunks and bats.

- Human bites-HBV, HCV, HIV, and herpes simplex.

\section{Antibiotic Prophylaxis}

Prophylactic antibiotics should be prescribed for all human and cat bites less than $72 \mathrm{~h}$ old even if there is no sign of infection. For other animal bites then antibiotics should be prescribed if the bite involves the hand, foot and face, joints, tendons or where there are suspected fractures. Antibiotics should also be prescribed for people who are at increased risk of infection e.g. diabetes, asplenia, cirrhosis, immunosuppressed, or who have a prosthetic joint or valve.

Co-amoxiclav (amoxycillin and clavulanic acid) is the first choice for both prophylaxis and treatment and should be given for 7 days. For adults, the recommended dose is $500 / 125 \mathrm{mg}$ tds and for children $40 \mathrm{mg} / \mathrm{kg}$ tds (based on amoxycillin component). If the individual is known or suspected to be allergic to penicillin, then a tetracycline (e.g. doxycycline $100 \mathrm{mg}$ bd) and metronidazole (500 mg tds) or erythromycin (or clarithromycin) and metronidazole can be used. Specialist advice should be sort for children who are penicillin allergic and for pregnant women.

Anyone with severe infection or who is clinically unwell should be referred to hospital. Tetanus vaccine should be given if the primary course or last booster was more than 10 years ago. Human tetanus immunoglobulin should be considered for tetanus-prone wounds (e.g. soil contamination, puncture wounds, signs of 
devitalized tissue, or for wounds sustained more than $6 \mathrm{~h}$ old). If the person has never been immunized or is unsure of their tetanus status, then a full three-dose course, spaced at least a month apart, should be given.

\section{Management of Suspected Viral Infections from Human Bites}

Penetrating bite wounds that involve only saliva may present a risk of HBV if the perpetrator belongs to a high-risk group. For management see "Disease Prevention" and "Management in Custody" in section "Hepatitis B". HCV and HIV are only a risk if blood is involved. The relevant management is dealt with in "Management in Custody" in section "Hepatitis C" and "Management in Custody of Staff/Victims in Contact with Disease" in section "Human Immunodeficiency Virus". Consultation with a virologist or communicable diseases doctor should be sought at the earliest opportunity.

\section{Infections Transmitted Through the Respiratory Route}

\section{General Information}

Respiratory tract infections are common, are usually mild and self-limiting, although they may require symptomatic treatment with paracetamol or a non-steroidal antiinflammatory. These include the common cold (80\%-rhinoviruses and 20\%coronaviruses), adenoviruses, influenza and parainfluenza, and during the summer and early autumn - enteroviruses. Special attention should be given to asthmatics or the immunocompromised detainee, as infection in these people may be more serious particularly if the lower respiratory tract is involved.

The following section includes respiratory pathogens of special note as they may pose a risk to both the detainee and/or staff who come into close contact.

\section{Meningococcal Meningitis (Neisseria meningitidis)}

\section{General Information and Epidemiology}

There are six meningococcal capsular groups of Neisseria meningitidis: A, B, C, $\mathrm{W} 135 \mathrm{X}$ and $\mathrm{Y}$ that are responsible for nearly all invasive infections in humans. The prevalence of the different types varies from country to country. In the UK nasopharynx carriage prevalence is around 5\% in infants and reaches a peak at around aged 19 of $24 \%$. The rate declines to about $8 \%$ in adulthood. The risk of invasive disease following acquisition varies with environmental and host factors. Established carriers rarely get invasive disease.

In 1999 the MenC conjugate vaccine was introduced and vaccination programs over the years have substantially reduced the number of cases in the under $18 \mathrm{~s}$. A secondary benefit of the reduced carriage rate in immunized adolescents was to reduce the number of cases in older age groups. MenC has remained well controlled with 20-30 cases occurring annually over the last 10 years. Of the current cases many occur in people who were born outside the UK and who may not have been vaccinated. 
Cases of MenW were associated with the Hajj pilgrimage in the early 2000 but this has been controlled by the mandatory introduction of MenACWY vaccination for all pilgrims going to Saudi Arabia. Since then MenW have accounted for about $5 \%$ of invasive disease until 2010 when cases increased with a peak in 2015/16 of more than 200 cases in that year. The cause was identified as a hypervirulent strain which was responsible for severe disease with high fatality rates in South America, From August 2015 the UK introduced an emergency MenACWY vaccination program for adolescents. The conjugate vaccine is now routinely given to 14 year olds with a catch up for 14-18 years and new university students up to their 25th birthday. This has been effective as by the end of August 2016 there was a 69\% decrease of MenW disease in those who left school in the summer of 2015.

MenB disease has declined in the UK over the last 10 years. Around $26 \%$ of MenB cases occur in the first year of life with $60 \%$ occurring during the first 5 years. A second smaller peak occurs in 15-19 year olds. Since September 2015 MenB vaccine has been incorporated into the UK childhood program and there has already been a fall in the number of cases [64].

\section{Symptoms}

Following an incubation period of 3-5 days [65, 66], disease onset may either be insidious with mild prodromal symptoms or florid. Early symptoms and signs include malaise, fever and vomiting. Severe headache, neck stiffness, photophobia, drowsiness and a rash may develop. The rash may be petechial or purpuric and characteristically does not blanche under pressure. Meningitis in infants is more likely to be insidious in onset and lack the classical signs. In approximately 15-20\% of cases, septicemia is the predominant feature. Even with prompt antibiotic treatment, the case fatality rate is 3-5\% in meningitis and $15-20 \%$ in those with septicemia [33]. Meningococcal meningitis and septicemia are statutorily notifiable under health protection legislation in the UK. All cases where a diagnosis of meningococcal disease is suspected should be reported to the Health Protection Team without delay.

\section{Period of Infectivity}

A person should be considered infectious until the bacteria are no longer present in nasal discharge. With treatment, this is usually approximately $24 \mathrm{~h}$.

\section{Routes of Transmission}

The disease is spread through infected droplets or direct contact from carriers or those who are clinically ill. It requires prolonged and close contact, so is a greater risk for people who share accommodation, utensils, and intimate kissing. It must also be remembered that unprotected mouth-to-mouth resuscitation can also transmit disease but this should never occur in the custody setting where pocket masks and bag valve masks are available.

The risk of illness in close contacts is highest in the first $48 \mathrm{~h}$ of disease onset in the index case. The absolute risk of developing a second case of invasive meningococcal disease (IMD) is 1/300 if no chemoprophylaxis is given. Antibiotics are 
given to close contacts of cases to eliminate established carriage and to eradicate carriage in those who have newly acquired the invasive strain.

Transient contact with an index case such as during travel in a plane, bus or car does not justify prophylaxis. European Centre for Disease Prevention and Control (ECDC) guidance indicates flight contact tracing only if there was intense exposure to nasopharyngeal sections. In the USA antibiotic prophylaxis would be recommended for passengers seated next to an index case for more than $8 \mathrm{~h}$.

\section{Management in Custody}

Anyone suspected of having meningococcal disease should be sent straight to hospital. Antibiotic prophylaxis is only recommended for those who have had prolonged close contact with a case during the 7 days before the onset of illness, or for those who have had transient close contact but have been directly exposed to large droplets and respiratory excretions around the time of hospitalization. The latter situation may occur in custody with a detainee who is clinically unwell and who coughs into the staff member's face. Respiratory droplets in the eyes is not a case for antibiotics but there is a low risk of meningococcal conjunctivitis. Staff exposed in this way should be advised to seek medical treatment promptly if conjunctivitis develops within 10 days of exposure. Any staff member who thinks they have been exposed should seek advice from their Occupational Health Department or local Health Protection Team.

Ciprofloxacin is the prophylactic antibiotic of choice in the UK, for all age groups and in pregnancy. It is given as a single dose and does not interfere with oral contraceptives and is readily available in pharmacies. In cases of ciprofloxacin hypersensitivity rifampicin is a viable alternative but this requires multiple doses, can inhibit oral contraceptives and is only available through hospital pharmacies. Antibiotic prophylaxis should be given as soon as possible and ideally within $24 \mathrm{~h}$ after the diagnosis of the index case. However, antibiotics and vaccine may still be considered up to 28 days later.

Meningococcal vaccination is offered to those at prolonged contact with the index cases. This provides longer term protection and can reduce the chance of late cases. Health care workers or those working in custody suites do not need to be vaccinated routinely because of the low risk of exposure. The threshold for given chemoprophylaxis would however be lowered in those staff members who were immunocompromised [64].

\section{Tuberculosis}

\section{Prevalence and Epidemiology}

Human tuberculosis (TB) is caused by infection with Mycobacterium tuberculosis, M. bovis or M. africanum. It is a notifiable disease under legislation specific to individual countries, for example in the UK this comes under the Public Health (Control of Disease) Act 1984. In 1993, the WHO declared TB to be a global emergency with 
an estimated seven to eight million new cases and three million deaths occurring each year, the majority of which were in Asia and Africa.

In 2017 it was estimated that ten million new cases of TB occurred globally (5.8 million men, 3.2 million women and one million children). There were cases in all countries and all age groups but overall $90 \%$ were adults $(>15)$ and $9 \%$ had concomitant HIV and of those $72 \%$ were living in Africa. Two thirds of the TB cases were from eight countries, India, China, Indonesia, Philippines, Pakistan, Nigeria, Bangladesh, and South Africa. Only $6 \%$ of global cases were in the WHO European region (3\%) and WHO Region of the Americas (3\%) [67].

World-wide in 2017 it is estimated that around 558,000 people developed TB that was resistant to Rifampicin (RR-TB) and of these $82 \%$ had multi-drug resistant TB (MDR-TB), India, China and the Russian Federation accounted for almost $50 \%$ of the cases with India accounting for $24 \%$. Some $8.5 \%$ of the MDR-TB cases in 2017 were estimated to have extensively drug resistant TB (XDR-TB).

About 1.7 billion people in the world have latent TB that can be reactivated and are therefore at risk of active disease. This represents just under a quarter of the world population.

\section{TB in England}

In 1999 the Enhanced Surveillance system was introduced in England and Wales and in the following year in Northern Ireland. The number of cases of TB rose steadily from 6686 in 2000 to a peak of 8919 cases reported in 2011 after which the numbers started to decline. The overall UK rate in 2017 was reported as $8.4 / 100,000$ down from 14.1/100,000 in 2011. England had the highest rate 9.2/100,000 and Wales the lowest 3.4/100,000. Despite the overall the drop since 2011 England continues to have one of the highest TB rates in Western Europe [68].

Data collected throughout England averaged over a 3 year period of 2015-2017 show that London, Manchester and Birmingham have the highest rates $(24.3,23.4$ and 22.8 per 100,000 population respectively). This has been attributed to its highly mobile population, the variety of ethnic groups, a high prevalence of HIV, and the emergence of drug-resistant strains.

A similar picture was initially found in the USA, when there was a reversal of a long-standing downward trend in 1985. However, between 1986 and 1992, the number of cases increased from 22,201 to 26,673 [69]. There were also serious outbreaks of multi-drug-resistant TB (MDR-TB) in hospitals in New York City and Miami [70]. Factors pertinent to the overall upswing included the emergence of $\mathrm{HIV}$, the increasing numbers of immigrants from countries with a high prevalence of tuberculosis, and perhaps more significantly, the stopping of categorical federal funding for control activities in 1972. The latter led to a failure of the public health infrastructure for TB control. Since 1992, the trend has reversed as the CDC transferred most of its funds to tuberculosis surveillance and treatment programs in states and large cities. In 20179093 cases were reported to the CDC giving an overall TB rate of 2.8 cases/100,000 persons. More than 50\% of all TB was reported in four states (California, Florida, New York and Texas). The TB rate was 14.6 times higher 
in non US born persons than in US born persons and although this represented a decrease in previous years there was only a $0.9 \%$ decrease in the non US born persons compared with $7 \%$ in those born in the USA. The HIV status was known for $86 \%$ of all TB cases reported in 2107 and $5.6 \%$ were shown to be co infected with HIV [71].

The acquisition of tuberculosis infection is not necessarily followed by disease as the infection may heal spontaneously. It may take weeks or months before disease becomes apparent or infection may remain dormant for years before reactivation in later life especially if the person becomes debilitated or immunocompromised. Contrary to popular belief, the majority of cases of TB in immunocompetent people pass unnoticed. Of reported cases, $75 \%$ involve the lung, while non-respiratory (e.g. bone, heart, kidney, brain) or dissemination (miliary TB) are more common in immigrant ethnic groups and the immunocompromised [72]. They are also more likely to develop resistant strains. In the general population, there is an estimated $10 \%$ lifetime risk of tuberculosis infection progressing to disease [73].

In 2017 there were a total of 464,633 cases reported of TB in people living with HIV. This represents $51 \%$ of the estimated number of cases indicating the degree of under reporting. This is very significant as TB is more likely to progress to active TB in HIV positive individuals with a greater than $50 \%$ lifetime risk [74]. TB can also lead to a worsening of HIV with an increase in viral load [75]. Therefore, the need for early diagnosis is paramount but it can be more difficult as pulmonary TB may present with non-specific features, e.g. bilateral, unilateral or lower lobe shadowing [76].

\section{Symptoms of Pulmonary TB}

After an incubation of 4-12 weeks, symptoms may develop (see Table 10.7).

\section{Routes of Transmission}

The main route is airborne through infected droplets, but prolonged or close contact is needed. Non-respiratory disease is not considered a risk unless the Mycobacterium is aerosolized under exceptional circumstances (e.g. during surgery) or there are open abscesses.

Table 10.7 Symptoms of pulmonary TB

\begin{tabular}{l}
\hline Cough lasting $>3$ weeks or $>2$ weeks in endemic countries \\
\hline Fatigue \\
\hline Anorexia and weight loss \\
\hline Fever and night sweats \\
\hline Mild haemoptysis (rusty colored) \\
\hline Cough with phlegm \\
\hline Swollen lymph glands
\end{tabular}




\section{Period of Infectivity}

A person is considered infectious as long as viable bacilli are found in induced sputum. Untreated or incompletely treated people may be intermittently sputumpositive for years.

Following 2 weeks of appropriate treatment, the individual is usually considered as non-infectious. This period may be extended for treatment of MDR-TB or XDR-TB or for those with concomitant HIV. Patient compliance also plays an important factor.

\section{At-Risk Groups}

The risk of infection is directly proportional to the degree of exposure. More severe disease occurs in the malnourished, or the immunocompromised (e.g. HIV etc.) and substance misusers.

Immunocompromised people are at special risk of MDR-TB, XDR-TB or Mycobacterium avium-intracellulare (MAI) although more recently cases resistant to treatment have been described in immunocompetent people.

\section{Management in Custody}

Staff with disease should stay off work for 2 weeks whilst treatment is taking effect. You no longer have to wait to be sputum negative as the bacilli can persist for months even though you are no longer infectious. Staff in contact with disease who have been vaccinated with BCG are at low risk of acquiring disease, but should minimize the time spent in the cell. Those who have not received BCG or who are immunocompromised should avoid contact with the detainee wherever possible. Any staff member who is pregnant, regardless of BCG status or type of TB, should avoid contact all together.

Anyone who has had a significant exposure should report to Occupational Health or their GP if no other route exists for testing and treatment if needed. They should also be educated as to the symptoms of TB. Anyone who is likely to come into repeated contact with individuals at risk of TB should receive BCG (if they have not already done so) regardless of age, even though there is evidence to suggest that BCG administered in adult life is less effective. This does not apply to immunocompromised individuals or pregnant women. In the latter case, vaccination should preferably be deferred until after delivery. HIV positive people should never be given BCG.

Detainees with disease (whether suspected or diagnosed) who have not been treated or treatment is incomplete (i.e. less than 2 weeks) should be kept in custody for the minimum time possible. Immunocompromised individuals with TB are usually too ill to be detained, but if they are, they should be considered at greater risk of transmitting disease to staff. Any detainee with disease should be encouraged to cover their mouth and nose when coughing and sneezing.

Staff should wear gloves when in contact with the detainee and when handling clothing and bedding. Any bedding should be bagged after use and laundered or 
incinerated. The cell should be deemed out of action until it has been ventilated and professionally decontaminated, although there is no hard evidence to support that there is a risk of transmission from this route.

\section{Severe Acute Respiratory Syndrome SARS-CoV and Middle East Respiratory Syndrome MERS-CoV}

On March 142,003, the WHO issued a global warning to health authorities about a new atypical pneumonia called SARS. The earliest case was believed to have originated in the Guandong province of China on 16 November 2002. The causative agent was identified as a new Corona virus-SARS-CoV [77, 78]. By the end of June 2003, 8422 cases had been reported from 31 different countries with a total of 916 deaths. Approximately $92 \%$ of cases occurred in China (including Hong Kong, Taiwan and Macao). The case fatality rate varied from $<1 \%$ in people less than 24 years old, to over $50 \%$ in persons 65 or older. On 5 July 2003, the WHO reported that the last human chain of transmission of SARS had been broken and lifted the ban from all countries. However, they warned that everyone should remain vigilant, as resurgence of SARS was still a possibility and this indeed proved the case with reports ongoing until May 2004. Since then, there have been no further reported cases. Knowledge about the epidemiology and ecology of SARS-CoV and the disease remains limited; however, the experience gained from the previous outbreak enabled the disease to be contained rapidly-reflected in the few cases reported since December. There is still no specific treatment or preventative vaccine that has been developed to date.

Another coronavirus, MERS-CoV was identified in Saudi Arabia in 2012 which causes a similar clinical picture to SARS. This zoonotic disease is acquired by humans through direct or indirect contact with dromedary camels. Since 201227 countries have reported cases of MERS including Algeria, Austria, Bahrain, China, Egypt, France, Germany, Italy, Jordan, Malaysia, the Netherlands, Oman, Philippines, Qatar, Saudi Arabia, Thailand, Tunisia, Turkey the UK, the USA and Yemen. Over $90 \%$ of all reported cases have been from the Kingdom of Saudi Arabia. Cases outside the Middle East have originated in travellers to that area. There was one large outbreak in the Republic of Korea with 186 cases reported Approximately $35 \%$ of patients with MERS have died but this may be an overestimate as milder cases that are not being reported are not included. As of the 3rd September 20182241 cases of MERS-CoV have been reported to WHO with at least 795 deaths [79].

PHE reported a laboratory confirmed case in August 2018 from a resident of the Middle East who had travelled to the UK. The last case reported from the UK was in 2013. The risk of infection to UK residents remains very low but HCPs should remain vigilant. It is important that any suspected cases are identified early and reported to local health protection teams as soon as possible.

\section{Incubation Period and Symptoms}

The incubation period for SARS is around 3-6 days (maximum 10 days), and for MERS-CoV 2-14 days with a median of 5 days. 
The following clinical case definition of SARS has been developed for public health purposes [80].

A person with a history of:

- Fever (at least $38^{\circ} \mathrm{C}$ )

- And, one or more symptoms of lower respiratory tract illness (cough, difficulty in breathing, dyspnea)

- And, radiographic evidence of lung infiltrates consistent with pneumonia or Respiratory Distress Syndrome, or post mortem findings of the above with no identifiable cause

- And, no alternative diagnosis can fully explain the illness.

The clinical symptoms of MERS-CoV ranges from asymptomatic or mild respiratory symptoms to severe acute respiratory disease and death. Pneumonia is common and gastrointestinal symptoms including diarrhea have also been reported. Severe cases require hospitalization and mechanical ventilation. More severe disease occurs in older people, those who are immunosuppressed or who have chronic diseases such as cancer, renal disease, diabetes and other chronic lung diseases. The algorithm for possible cases of MERS-CoV can be found at https://assets.publishing.service.gov.uk/government/uploads/system/uploads/attachment_data/ file/732267/Algorithm_case_v31-Aug2018.pdf.

\section{Route of Transmission}

SARS is spread by close contact with an infected individual via aerosol or infected droplets. Most cases occurred in hospital workers caring for an index case or their close family members. The virus can also be spread by hands and other objects the droplets have touched. The virus has also been shown to survive in stool for up to 4 days.

For MERS-CoV the route is thought to be from dromedary camels to humans but is not fully understood. Human to human transmission does not occur easily but clusters of cases have occurred in healthcare facilities where infection control practices have been poor. No sustained human to human transmission of MERS-CoV has been documented anywhere in the world [81].

\section{Management in Custody}

There have been no cases of SARS since 2004, but cases of MERS-CoV do continue to occur so should be borne in mind for returning travelers who present with respiratory symptoms. There is no vaccine or medicine specific for MERS-CoV so treatment is just supportive and is based on the clinical condition of the patient.

\section{Infections Transmitted Through the Faecal-Oral Route}

\section{General Considerations}

The most consistent feature of diseases transmitted through the fecal-oral route is diarrhea (see Table 10.8). Infective agents include bacteria, viruses and protozoa. 


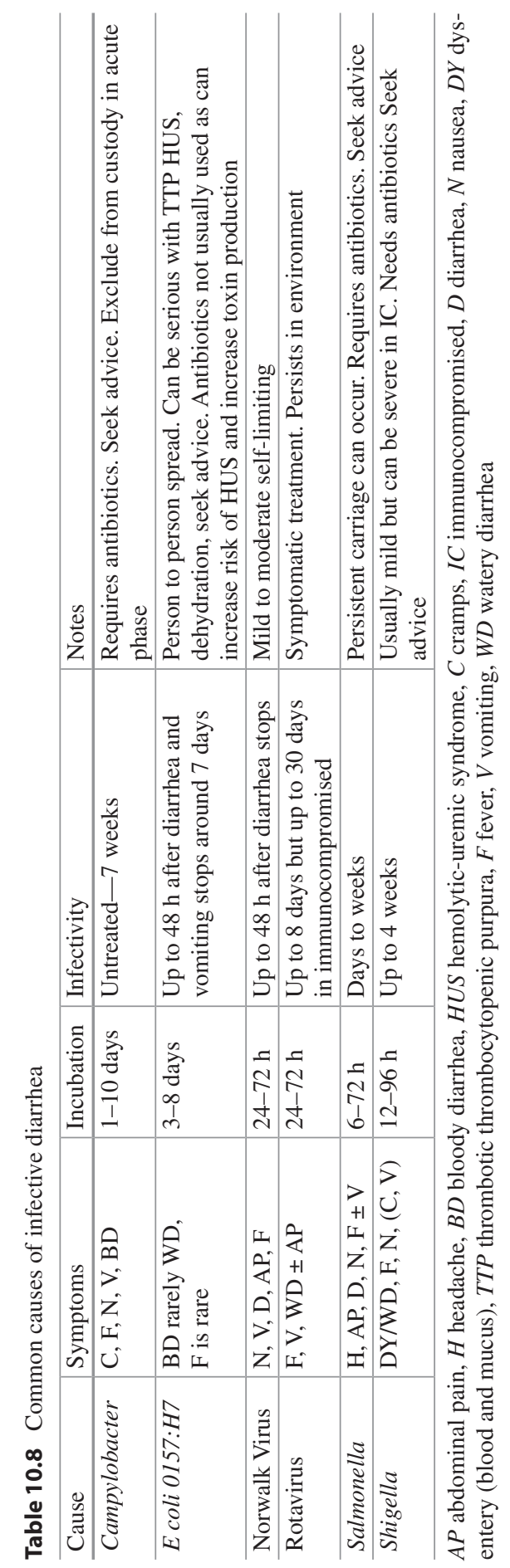


Since the causes are numerous, it is beyond the remit of this chapter to cover them all. It is safest to treat all diarrhea as infectious unless the detainee has a proven noninfectious cause (e.g. Crohn's disease, ulcerative colitis).

All staff should wear gloves when in contact with the detainee or handling clothing, bedding etc. and contaminated articles should be laundered or incinerated. The cell should be professionally cleaned after use paying particular attention to the toilet area.

\section{Hepatitis A}

\section{Epidemiology and Prevalence}

This viral hepatitis occurs worldwide with variable prevalence. It is highest in countries where hygiene is poor and infection occurs all year round. In temperate climates, the peak incidence is in autumn and winter, but the trend is becoming less marked.

All age groups are susceptible if they are non-immune or have not been vaccinated. In developing countries, the disease occurs in early childhood, whereas the reverse is true in countries where the standard of living is higher.

In the UK, there has been a gradual decrease in the number of reported cases from 1990 to 2000 [82, 83]. This is due in part to improved standards of living and the introduction of an effective vaccine. In 2015 there were 330 confirmed cases of hepatitis A. The highest incidence occurred in the 15-34-year-old age group [84].

In the UK between July 2016 and January 2017, 37 confirmed cases of hepatitis A were reported from eight areas in England and Northern Ireland and of those 28 were identified among MSM [85]. Since 2016, 1173 confirmed cases of hepatitis A have been reported from 15 EU countries. Most cases were reported among MSM [86]. Cases in the UK and the EU have been with identical strains prompting the European Centre for Disease Prevention and Control (ECDC) to issue a rapid risk assessment in December 2016 [86]. The outbreak emphasized the need for awareness of hepatitis A among the MSM population.

\section{Symptoms}

The clinical picture ranges from asymptomatic infection through a spectrum to fulminant hepatitis. Unlike HBV and HCV, HAV does not persist or progress to chronic liver damage. Infection in childhood is often mild or asymptomatic, but in adults tends to be more severe.

Following an incubation period of 15-50 days (mean 28 days), symptomatic infection starts with the abrupt onset of jaundice anything from 2 days to 3 weeks after the anicteric phase. It lasts for approximately the same length of time and is often accompanied by a sudden onset of fever. 
HAV infection can lead to hospital admission in all age groups, but is more likely with increasing age.

The overall mortality is less than $1 \%$, but $15 \%$ of people will have a prolonged or relapsing illness over $6-9$ months. Fulminant hepatitis occurs in $<1 \%$ of people, but is more likely over the age of 65 or in those with pre-existing liver disease. In hospitalized patients, case fatality ranges from $2 \%$ in $50-59$ year olds to nearly $13 \%$ in those older than 70 years [83].

\section{Period of Infectivity}

The individual is most infectious in the 2 weeks before the onset of jaundice when they are asymptomatic. This can make control of infection difficult since the disease is not recognized.

\section{Routes of Transmission}

The main route is fecal-oral through the ingestion of contaminated water and food. It can also be transmitted by close personal contact including homosexuals practicing anal intercourse and fellatio. There is a very slight risk from blood transfusions if the donor is in the acute phase of infection. It should not be considered a risk from needlestick injuries unless clinical suspicion of HAV is high.

\section{Risk Groups}

Risk groups include the homeless, MSM, PWID, travellers abroad who have not been vaccinated, patients with chronic liver disease and chronic infection with HBV and $\mathrm{HCV}$, employees and residents in day-care centers and hostels, sewage workers, laboratory technicians and those handling non-human primates.

Several large outbreaks have occurred among injecting drug users-some with an epidemiological link to prisons $[87,88]$. Transmission occurs during the viremia phase of the illness through sharing injecting equipment and via fecal-oral routes because of poor living conditions [89]. There have also been reports of HAV being transmitted through drugs that have been carried in the rectum. A study in Vancouver showed that $40 \%$ of injecting drug users had past infection of HAV and they also showed an increased prevalence among men who have sex with men [90].

\section{Management in Custody}

Staff with disease should report to Occupational Health and stay off work until the end of the infective period. Those in contact with disease (either through exposure at home or from an infected detainee) should receive prophylactic treatment as soon as possible (see below). 
To minimize the risk of acquiring disease in custody, staff should wear gloves when dealing with the detainee then wash their hands thoroughly. Gloves should only be disposed of in the clinical waste bags.

Detainees with disease should be kept in custody for the minimum time possible. They should only be sent to hospital if fulminant hepatitis is suspected. The cell should be quarantined after use and professionally cleaned. Any bedding or clothing should be handled with gloves and laundered or incinerated according to local policy. Detainees reporting contact with disease should be given prophylactic treatment as soon as possible (see section "Post exposure prophylaxis").

\section{Post exposure Prophylaxis}

Contacts of HAV should receive HAV vaccine (e.g. Havrix Monodose or Avaxim) if they have not been previously immunized or had disease. Human normal immunoglobulin (HNIG) $500 \mathrm{mg}$ deep im in gluteal muscle should be used in the following circumstances:

- The contact is aged 60 or over and it is within 14 days of exposure

- Also for close contacts within 14 days of exposure who are HIV positive and have a CD4 count $<200$ cells $/ \mathrm{mm}^{3}$

- For contacts who are immunosuppressed for other reasons within 14 days of exposure.

If time allows anyone needing HNIG should be tested for IgG antibodies to hepatitis A (anti-HAV IgG) [91].

Staff at higher risk of coming in contact with HAV should consider being vaccinated prior to exposure. Two doses of vaccine given 6-12 months apart provide around 25 years of protection. There is no specific treatment for HAV except supportive measures and symptomatic treatment.

\section{Exotica}

Although the chance of encountering a tropical disease in custody is small, it is worth bearing in mind. It is not necessary for a healthcare professional to be able to diagnose the specific disease, but simply to recognize that the detainee/staff member is ill and whether or not they need to be sent to hospital. This is best achieved by knowing the right questions to ask and carry out the appropriate examination. Tables 10.9, 10.10, and 10.11 should be used as an aide memoire in order not to miss some more unusual diseases.

Illustrative Cases 1. A police officer sustained a needle stick injury whilst searching a detainee's property. The needle penetrated his gloves and drew blood. The officer reported the injury immediately to the HCP who encouraged the puncture to bleed and washed the area well with soap and water and applied a plaster. 
Table 10.9 Suspicion of exotica? History and examination aide memoire

Has the detainee travelled to Africa, South East Asia, the Indian Sub-continent, Central/South America or the Far East in the last 6-12 months

Ascertain whether they received any vaccinations prior to travel and what

Ask if they took malaria prophylaxis, what type and whether they completed the course

Ask if they swam in any stagnant lakes during the trip

If yes to any of the above, ask if they have experienced any of the following symptoms:

A fever/hot or cold flushes/shivering

Diarrhea \pm abdominal cramps \pm blood or slime in the stool

A rash

Persistent headaches \pm light sensitivity

Nausea or vomiting

Aching muscles/joints

A persistent cough (dry or productive) lasting at least 3 weeks

Table 10.10 Examples of tropical diseases that present with a fever

\begin{tabular}{l|l|l|l|l}
\hline Disease & Countries & Incubation & How transmitted & Management \\
\hline Dengue & $\begin{array}{l}\text { Caribbean and } \\
\text { S. America, Asia, } \\
\text { Africa }\end{array}$ & $3-14$ days & $\begin{array}{l}\text { Mosquito-no } \\
\text { human to human in } \\
\text { the UK }\end{array}$ & $\begin{array}{l}\text { Usually } \\
\text { symptomatic }\end{array}$ \\
\hline Ebola & Sub Saharan Africa & 2-21 days & $\begin{array}{l}\text { Body fluids from } \\
\text { infected people }\end{array}$ & $\begin{array}{l}\text { Isolation and } \\
\text { hospitalisation }\end{array}$ \\
\hline $\begin{array}{l}\text { HFRS }- \\
\text { Hanta virus }\end{array}$ & $\begin{array}{l}\text { Europe, Asia, } \\
\text { Africa }\end{array}$ & $\begin{array}{l}\text { 2 days to } \\
8 \text { weeks }\end{array}$ & $\begin{array}{l}\text { Rat, mouse and } \\
\text { vole excreta and } \\
\text { body fluids }\end{array}$ & Hospital \\
\hline $\begin{array}{l}\text { HPS }- \text { Hanta } \\
\text { virus }\end{array}$ & $\begin{array}{l}\text { North and South } \\
\text { America }\end{array}$ & $\begin{array}{l}2 \text { days to } \\
8 \text { weeks }\end{array}$ & $\begin{array}{l}\text { Rat, mouse and } \\
\text { vole excreta and } \\
\text { body fluids }\end{array}$ & Hospital \\
\hline Lassa fever & West Africa & $6-21$ days & $\begin{array}{l}\text { Rat urine and } \\
\text { excreta }\end{array}$ & $\begin{array}{l}\text { Isolation and } \\
\text { Hospitalisation }\end{array}$ \\
\hline Malaria & $\begin{array}{l}\text { Sub Saharan } \\
\text { Africa, some parts } \\
\text { of Asia and South } \\
\text { America, Vanuatu }\end{array}$ & $\begin{array}{l}7 \text { days to } \\
\text { 1 year }\end{array}$ & $\begin{array}{l}\text { Mosquito-no } \\
\text { human to human } \\
\text { transmission in the } \\
\text { UK }\end{array}$ & $\begin{array}{l}\text { May need urgent } \\
\text { treatment }\end{array}$ \\
\hline Yellow fever & $\begin{array}{l}\text { Sub Saharan Africa } \\
\text { and South America }\end{array}$ & 3-6 days & $\begin{array}{l}\text { Mosquito-no } \\
\text { human to human } \\
\text { transmission in the } \\
\text { UK }\end{array}$ & $\begin{array}{l}\text { Often needs } \\
\text { hospital } \\
\text { treatment }\end{array}$ \\
\hline
\end{tabular}

${ }^{a} H F R S$ haemorrhagic fever with renal syndrome

${ }^{\mathrm{b}} H P S$ hantavirus pulmonary syndrome

Details of the incident were recorded along with a medical history of the police officer and details of vaccinations received. The police officer reported that he had not had any hepatitis B vaccine. He had no underlying health concerns.

The HCP spoke with the detainee who admitted injecting drugs and to sharing needles. He last shared a needle more than 3 months ago and had no other risk fac- 
Table 10.11 Examples of tropical diseases that can present with diarrhoea

\begin{tabular}{|c|c|c|c|c|}
\hline Disease & Incubation & Infectivity & $\begin{array}{l}\text { Transmission } \\
\text { route }\end{array}$ & Management \\
\hline $\begin{array}{l}\text { Amoebic } \\
\text { dysentery }\end{array}$ & $\begin{array}{l}\text { Days to } \\
\text { months }\end{array}$ & Years & Oral-fecal & $\begin{array}{l}\text { Anti-parasitic treatment } \\
\text { e.g. metronidazole }\end{array}$ \\
\hline Cholera & $\begin{array}{l}\text { Hours to } \\
5 \text { days }\end{array}$ & $\begin{array}{l}3-5 \text { days after } \\
\text { recovery }\end{array}$ & Oral-fecal Vomit & Requires antibiotics \\
\hline Gardia & 3-25 days & Months & Oral-fecal & $\begin{array}{l}\text { Anti-parasitic treatment } \\
\text { e.g. tinidazole }\end{array}$ \\
\hline Malaria & $\begin{array}{l}7 \text { days to } \\
1 \text { year }\end{array}$ & None & None & $\begin{array}{l}\text { Urgent } \\
\text { treatment-hospital }\end{array}$ \\
\hline Typhoid $^{\mathrm{a}}$ & Up to 3 days & $\begin{array}{l}\text { Days to } \\
\text { weeks }\end{array}$ & Oral-fecal & Requires antibiotics \\
\hline
\end{tabular}

Typhoid can also present as a fever

tors. The HCP asked if the detainee was willing to provide a sample of blood which would be tested for hepatitis B, HIV and hepatitis C. The detainee agreed and signed a consent form which was countersigned by the HCP and an independent police officer. Ten mLs of clotted blood was taken from the detainee which was given to the police officer involved who took it to the designated hospital. A $10 \mathrm{~mL}$ clotted sample of blood was taken at the hospital from the police officer as a baseline blood to be stored.

Testing of the detainee's blood revealed the following:

HBs Ag positive

$\mathrm{HCV}$ antibody positive

HIV antibody/Ag negative

Based on these findings and the unvaccinated status of the police officer-HBIG was administered into the gluteal region along with the hepatitis B vaccination in to the deltoid region. Arrangements were made to follow up the police officer to receive two further doses of hepatitis B vaccine at 4 and 8 weeks. Further screening for hepatitis C RNA at 6 and 12 weeks and for HCV antibodies at 12 and 24 weeks. A test for HBsAg would also be conducted at 24 weeks.

2. A detainee was arrested and brought into custody. Whilst filling in the risk assessment form the Custody Sergeant became aware that the detainee was on medication for pulmonary TB.

The HCP was asked to examine the detainee and established that the diagnosis of TB had been made 3 weeks ago.

The detainee had been prescribed isoniazid and rifampicin for 6 months with ethambutol and pyrazinide for the first 2 months. She reported that she had taken her medication every day for the last 20 days. This was evidenced by the number of tablets that had gone from the supply given. She said that she was feeling less tired and was no longer getting night sweats.

The HCP concluded that with such good compliance the detainee was unlikely to be infectious now and was therefore safe to remain in custody. 


\section{Key Points}

- The aim of adopting standard precautions with all personnel is to prevent transmission of BBVs by considering that blood and other body fluids are potentially infectious.

- The vulnerable population of patients seen in police custody are at risk of a number of infections due to general poor health, intravenous drug use, and social circumstances. There needs to a high index of suspicion and careful consideration as to whether treatment is required, including referral to hospital.

\section{Self-Assessment Exercises}

1. Place these hepatitis B markers in order of infectivity starting with the least infectious and give the $\%$ chance of acquisition of hepatitis B following a needle stick injury for each:

HBsAg, HBeA, HBeAg, HBSA

2. When is the earliest time for detecting (a) antibodies, (b) RNA following infection with hepatitis $\mathrm{C}$ virus?

3. (a) What is the current recommended regime for PEP in the UK?

(b) How long after exposure can PEP be considered?

4. When would you send a detainee or staff member with chicken pox to hospital? Give at least two examples

5. What are the main criteria for giving prophylactic antibiotics following human and other animal bites? Name the first choice of antibiotic and an alternative for people with allergies to penicillin.

\section{References}

1. UK Health Guidelines (1998) Guidance for clinical health care workers: protection against infection with blood-borne viruses: recommendations of the Expert Advisory Group on AIDS and the Advisory Group on Hepatitis [HSC 1998/063]. NHS Executive, London, UK

2. Standard precautions in USA. https://www.cdc.gov/oralhealth/infectioncontrol/summaryinfection-prevention-practices/standard-precautions.html. Accessed 5 Apr 2019

3. Prevention and Management of infections in Health Care settings South Australia. https://www. sahealth.sa.gov.au/wps/wcm/connect/public+content/sa+health+internet/clinical+resources/ clinical+topics/healthcare+associated+infections/prevention+and+management+of+infection s+in+healthcare+settings. Accessed 5 Apr 2019

4. Bolyard EA, Tablan OC, Williams WW, Pearson ML, Shapiro CN, Deitchman SD, and the Hospital Infection Control Practices Advisory Committee (1998) Guideline for infection control in health care personnel. Am J Infect Control 26:289-354

5. WHO Global Hepatitis Report 2017. http://www.who.int/hepatitis/publications/global-hepatitis-report2017/en/. Accessed 5 Apr 2019

6. Hepatitis B virus. http://www.hse.gov.uk/biosafety/blood-borne-viruses/hepatitis-b.htm. Accessed 5 Apr 2019

7. Centers for Disease Control (CDC) (1988) Perspectives in disease prevention and health promotion update. Universal precautions for prevention of transmission of human immuno-deficiency 
virus, hepatitis B virus and other bloodborne pathogens in health-care settings. MMWR Morb Mortal Wkly Rep 37:377-388

8. Acute Hepatitis B (England) Annual Report 2016. https://assets.publishing.service.gov.uk/ government/uploads/system/uploads/attachment_data/file/643558/hpr3117_hepB_ann.pdf. Accessed 5 Apr 2019

9. Shooting up: infections among people who inject drugs in the UK 2017, an update November 2018. https://assets.publishing.service.gov.uk/government/uploads/system/uploads/attachment_data/file/756502/Shooting_up_2018.pdf. Last accessed 8 Apr 2019

10. Martinson FE, Weigle KA, Royce RA, Weber DJ, Suchindran CM, Lemon SM (1998) Risk factors for horizontal transmission of hepatitis B in a rural district in Ghana. Am J Epidemiol 147:478-487

11. Verma G, Dalai P, Bapat M, Rathi P, Abraham P (2003) Familial clustering of hepatitis B infection: study of a family. Indian J Gastroenterol 22:22-23

12. Erol S, Ozkurt Z, Ertek M, Tasyaran MA (2003) Intrafamilial transmission of hepatitis B in the Eastern Anatolian region of Turkey. Eur J Gastroenterol Hepatol 15:345-349

13. Public Health England Health and Justice Review 2017/18. https://assets.publishing.service.gov.uk/government/uploads/system/uploads/attachment_data/file/725776/Health_and_ Justice_Annual_Review_2017-2018.pdf. Accessed 5 Apr 2019

14. Immunisation Against Infectious disease. Chapter 18. Hepatitis B. https://assets.publishing.service.gov.uk/government/uploads/system/uploads/attachment_data/file/628602/ Greenbook_chapter_18.pdf. Accessed 5 Apr 2019

15. World Health Organisation Global Hepatitis Report 2017. http://www.who.int/hepatitis/publications/global-hepatitis-report2017/en/. Accessed 5 Apr 2019

16. Frank C, Mohamed MK, Strickland GT (2000) The role of the parenteral antischistosomal therapy in the spread of hepatitis C virus in Egypt. Lancet 355:887-891

17. Hepatitis C Epidemiology in the United States. https://www.hepatitisc.uw.edu/pdf/screeningdiagnosis/epidemiology-us/core-concept/all. Accessed 5 Apr 2019

18. PHE Hepatitis C in England. 2018 report. http://www.hcvaction.org.uk/sites/default/files/ resources/Hepatitis\%20C\%20in\%20England\%202018\%20report.pdf. Last accessed 5 Apr 2019

19. Chief Medical Examiner, Sir Liam Donaldson (2002) Hepatitis C strategy for England. Department of Health, London, UK

20. Ramsay ME, Balogun MA, Collins M, Balraj V (1998) Laboratory surveillance of hepatitis C virus in England and Wales: 1992-1996. Commun Dis Public Health 1:89-89

21. Treatment for hepatitis C. https://www.nhs.uk/conditions/hepatitis-c/treatment/. Accessed 5 Apr 2019

22. HIV and Chronic HCV co-infection prevalence in England highest with MSM. http://www. aidsmap.com/HIV-and-chronic-HCV-co-infection-prevalence-in-England-highest-amongMSM/page/3319032/. Accessed 5 Apr 2019

23. WHO fact sheet hepatitis D. https://www.who.int/en/news-room/fact-sheets/detail/hepatitis-d. Accessed 5 Apr 2019

24. Hepatitis D, Sean R Lacey, Assistant Professor, Department of Medicine, Case Western Reserve University. http://emedicine.medscape.com/article/178038-overview. Accessed 5 Apr 2019

25. The Global HIV/AIDS Epidemic. https://hiv.gov/hiv-basics/overview/data-and-trends/globalstatistics. Accessed 5 Apr 2019

26. HIV in the UK Report. https://assets.publishing.service.gov.uk/government/uploads/system/ uploads/attachment_data/file/602942/HIV_in_the_UK_report.pdf. Accessed 5 Apr 2019

27. Trends in new HIV diagnoses and people receiving HIV related care in the UK. Data to the end of December 2017. https://assets.publishing.service.gov.uk/government/uploads/system/ uploads/attachment_data/file/738222/hpr3218_hiv17_v2.pdf. Accessed 5 Apr 2019

28. National HIV Surveillance Tables. www.gov.uk/government/statistics/hiv-annual-data-tables. Accessed 5 Apr 2019

29. Limb S, Kawar M, Forster GE (2002) HIV post-exposure prophylaxis after sexual assault: the experience of a sexual assault service in London. Int J STD AIDS 13:602-605 
30. UK Guidelines of the use of HIV post-exposure prophylaxis following sexual exposure (PEPSE) 2015. https://www.bashhguidelines.org/media/1027/pepse-2015.pdf. Accessed 5 Apr 2019

31. Jochimsen EM (1997) Failures of zidovudine post exposure prophylaxis. Am J Med 102:52-55

32. Hawkins DA, Asboe D, Barlow K, Evans B (2001) Seroconversion to HIV-1 following a needlestick injury despite combination post-exposure prophylaxis. J Inf Secur 43:12-15

33. Salisbury DM, Begg NT (1996) Immunisation against infectious disease. Her Majesty's Stationery Office, London, UK

34. Sinha DP (1996) Chickenpox-disease predominantly affecting adults in rural West Bengal. Int J Epidemiol 5:367-374

35. Centers for Disease Control and Prevention (1996) Prevention of varicella: recommendations of the Advisory Committee on Immunization Practices. MMWR Morb Mortal Wkly Rep 45:1-36

36. Fairley CK, Miller E (1996) Varicella-zoster virus epidemiology. A changing scene? J Infect Dis 174(suppl 3):314-319

37. Smego RA, Asperilla MO (1991) Use of Acyclovir for varicella pneumonia during pregnancy. Obstet Gynecol 78:1112-1116

38. Pastuszak AL, Levy M, Schick B et al (1994) Outcome after maternal varicella infection in the first 20 weeks of pregnancy. N Engl J Med 330:901-905

39. Miller E, Cradoc-Watson JE, Ridehalgh MK (1989) Outcome in newborn babies given antivaricella zoster immunoglobulin after perinatal maternal infection with varicella zoster virus. Lancet 2:371-373

40. Gilden DH, Vafai A, Shtram Y et al (1983) Varicella-zoster virus DNA in human sensory ganglia. Nature 306:478-480

41. Dworkin RH, Schmader KE (2001) Epidemiology and natural history of herpes zoster and post herpetic neuralgia. In: Watson CPN, Gershon AA (eds) Herpes zoster and postherpetic neuralgia, 2nd edn. Elsevier, New York, NY, pp 39-64

42. Desmond RA, Weiss HL, Arani RB et al (2002) Clinical applications for change-point analysis of herpes zoster pain. J Pain Symptom Manag 23:510-516

43. Gnann JW Jr, Whitley RJ (2002) Herpes zoster. N Engl J Med 347:340-346

44. Vaccine update Issue 286 September 2018. https://assets.publishing.service.gov.uk/government/uploads/system/uploads/attachment_data/file/744508/VU_286_september_2018.pdf. Accessed 5 Apr 2019

45. Haustein UF, Hlawa B (1989) Treatment of scabies with permethrin versus lindane and benzoyl benzoate. Acta Derm Venereol 69:348-351

46. Brown S, Becher J, Brady W (1995) Treatment of ectoparasitic infections; review of the English-language literature 1982-1992. Clin Infect Dis 20(suppl 1):S104-S109

47. Klutymans J, Van Belkum A, Verbrugh H (1989) Nasal carriage of Staphylococcus aureus: epidemiology and control measures. Infect Dis Clin N Am 3:901-913

48. Lowry FD (1998) Staphylococcus aureus infections. N Engl J Med 339:520-532

49. Centers for Disease Control and Prevention (1981) Community-acquired methicillinresistant Staphylococcus aureus infections-Michigan. MMWR Morb Mortal Wkly Rep 30:185-187

50. Saravolatz LD, Markowitz N, Arking L, Pohlod D, Fisher E (1982) Methicillin-resistant Staphylococcus aureus, epidemiologic observations during a community acquired outbreak. Ann Intern Med 96:11-16

51. M.J. Ellington et al. Panton-Valentine Leucocidin related disease in England and Wales. https://www.sciencedirect.com/science/article/pii/S1198743X14617900. Accessed 10/9/19

52. Shooting Up. Infections among injecting drug users in the United Kingdom 2008. An update (2009). https://webarchive.nationalarchives.gov.uk/20140629102649/http://www.hpa.org.uk/ Publications/InfectiousDiseases/BloodBorneInfections/ShootingUp/. Accessed 6 Apr 2019

53. Shooting up: Infections among people who inject drugs in the UK, 2016. An update November 2017. https://assets.publishing.service.gov.uk/government/uploads/system/uploads/attachment_data/file/663003/Shooting_Up_2017_report.pdf. Accessed 5 Apr 2019 
54. Summanen PH, Talan DA, Strong C et al (1995) Bacteriology of skin and soft tissue infections: comparison of infections in intravenous drug users and individuals with no history of intravenous drug use. Clin Infect Dis 20(Suppl 2):S279-S282

55. Bohlen LM, Muhlemann K, Dubuis O, Aebi C, Tauber MG (2000) Outbreak among drug users caused by a clonal strain of group a Streptococcus. Emerg Infect Dis 6(2):175-179. Dispatches—emerging infectious diseases. http://www.cdc.gov. Accessed Mar 2003

56. Lettington W (2002) Bacteriological skin and subcutaneous infections space in injecting drug users-relevance for custody. J Clin Forensic Med 9:65-69

57. Passaro DJ, Werner SB, McGee J, MacKenzie WR, Vugia DJ (1998) Wound botulism associated with black tar heroin among injecting drug users. JAMA 279:859-863

58. Brazier JS, Duerden BI, Hall V et al (2002) Isolation and identification of Clostridiumspp from infections associated with injection of drugs: experiences of a microbiological investigation team. J Med Microbiol 51:985-989

59. Greater Glasgow Health Board, SCIFH (2001) Unexplained illness among drug injectors in Glasgow. Eur Secur 4:500518

60. Kuylaylat MN, Barakat N, Stephan RN, Gutierrez I (1993) Embolization of illicit needle fragments. J Emerg Med 11:403-408

61. Ngaage DL, Cowen ME (2001) Right ventricular needle embolus in an injecting drug user: the need for early removal. Emerg Med J 18:500-501

62. Spanierman C (2004) Departments of Emergency Medicine and Pediatrics, Lutheran General Hospital of Oak Brook, Advocate Health System. eMedicine-Human Bites. http://www.emedicine.com/ped/topic246.htm. Accessed 10/9/19

63. Presutti JP (2001) Prevention and treatment of dog bites. Am Fam Physician 63:1567-1572

64. Guidance for the public health management of meningococcal disease in the UK. Update February 2018. https://assets.publishing.service.gov.uk/government/uploads/system/uploads/ attachment_data/file/688835/Public_health_management_of_meningococcal_disease_guidelines.pdf. Accessed 5 Apr 2019

65. Boutet R, Stuart JM, Kaczmarski E, Gray SJ, Jones M, Andrews N (2001) Risk of laboratoryacquired meningococcal disease. J Hosp Infect 49:282-284

66. Orr H, Kaczmarski E, Sarangi J, Pankhania B, Stuart J (2001) Cluster of meningococcal disease in rugby match spectators. Commun Dis Public Health 4:316-317

67. The Global Tuberculosis Report 2018 Executive Summary. https://www.who.int/tb/publications/global_report/tb18_ExecSum_web_4Oct18.pdf?ua=1. Accessed 6 Apr 2019

68. Chapter 7 current and emerging health protection issues. https://www.gov.uk/government/publications/health-profile-for-england-2018/chapter-7-current-and-emerging-health-protectionissues. Accessed 5 Apr 2019

69. Cantwell MF, Snider DE, Cauthen GM, Onorato IM (1994) Epidemiology of tuberculosis in the United States, 1985 through 1992. JAMA 272:535-539

70. Centers for Disease Control (1991) Nosocomial transmission of multi-drug resistant tuberculosis among HIV-infected persons-Florida, New York, 1988-1991. MMWR Morb Mortal Wkly Rep 40:585-591

71. Stewart RJ et al (2017) Tuberculosis USA. MMWR 67(11):317-323. https://www.cdc.gov/ mmwr/volumes/67/wr/mm6711a2.htm?s_cid=mm6711a2-e. Accessed 5 Apr 2019

72. Sepkowitz DV (1995) Tuberculosis in HIV-infected individuals (Chapter 5). In: Lutwick LI (ed) Tuberculosis - a clinical handbook. Chapman \& Hall Medical, London, UK

73. Murray JF (1989) The white plague: down and out, or up and coming? Am Rev Respir Dis 140:1788-1795

74. Selwyn PA, Hartel D, Lewis VA et al (1989) A prospective study of the risk of tuberculosis among intravenous drug users with human immunodeficiency virus infection. $\mathrm{N}$ Engl J Med 320:545-550

75. Wallis RS, Vjecha M, Amir-Tahmasseb M et al (1993) Influence of tuberculosis on human immunodeficiency virus (HIV-1): enhanced cytokine expression and elevated $\mathrm{B}_{2}$-microglobulin in HIV-1 associated tuberculosis. J Infect Dis 167:43-48 
76. Long R, Maycher B, Scalcini M, Manfreda J (1991) The chest roenterogram in pulmonary tuberculosis patients seropositive for human immunodeficiency virus type 1. Chest 99:123-127

77. Peiris JSM, Lais T, Poon LLM et al (2003) Coronavirus as a possible cause of severe acute respiratory syndrome. Lancet 361:1319-1325

78. Donnelly CA, Ghani AC, Leung GM et al (2003) Epidemiological determinants of spread of causal agents of severe acute respiratory syndrome in Hong Kong. Lancet 361:761-766

79. PHE Risk Assessment of MERS-CoV. https://www.gov.uk/government/publications/merscov-risk-assessment/phe-risk-assessment-of-mers-cov. Accessed 5 Apr 2019

80. World Health Organization (2003) Alert, verification and public health management of SARS in post-outbreak period. http://www.who.int/csr/sars/postoutbreak/en/. Accessed 14 Dec 2003

81. Middle East Respiratory Syndrome Coronavirus (MERS-COV). http://www.who.int/newsroom/fact-sheets/detail/middle-east-respiratory-syndrome-coronavirus-(mers-cov). Accessed 5 Apr 2019

82. Gay NJ, Morgan-Capner P, Wright J, Farrington CP, Miller E (1994) Age-specific antibody prevalence to hepatitis A in England: implications for disease control. Epidemiol Infect 113:113-120

83. Crowcroft NS, Walsh B, Davison KL, Gungabissoon U, PHLS Advisory Committee on Vaccination and Immunisation (2001) Guidelines for the control of hepatitis A infection. Commun Dis Public Health 4:213-227

84. Health Protection Report Volume 10 No 24. https://assets.publishing.service.gov.uk/government/uploads/system/uploads/attachment_data/file/540334/hpr2416_hepAC.pdf. Accessed 5 Apr 2019

85. Outbreak of hepatitis A associated with men who have sex with men (MSM), England, July 2016 to January 2017. https://www.eurosurveillance.org/docserver/fulltext/eurosurveillance/22/5/eurosurv-22-5-2.pdf?expires $=1539097725 \& \mathrm{id}=\mathrm{id} \&$ accname=guest\&checksum $=7$ 229AE7B3AE6F20963113FC7E402D883. Accessed 5 Apr 2019

86. Hepatitis A outbreaks in the EU/EEA mostly affecting men who have sex with men. Second update 19 May 2017. https://www.eurosurveillance.org/content/10.2807/1560-7917. ES.2017.22.5.30454. Accessed 5 Apr 2019

87. Harkess J, Gildon B, Istre GR (1989) Outbreaks of hepatitis A among illicit drug users, Oklahoma, 1984-1987. Am J Public Health 79:463-466

88. Hutin YJ, Bell BP, Marshall KL et al (1999) Identifying target groups for a potential vaccination program during a hepatitis A community outbreak. Am J Public Health 89:918-919

89. Hutin YJ, Sabin KM, Hutwagner LC et al (2000) Multiple modes of hepatitis A transmission among metamphetamine users. Am J Epidemiol 152:186-192

90. Ochnio JJ, Patrick D, Hom TG et al (2001) Past infection with hepatitis A among Vancouver Street youth, injection drug users and men who have sex with men; implications for vaccination programmes. CMAJ 165:293-297

91. Public Health control and management of hepatitis A. https://assets.publishing.service.gov. uk/government/uploads/system/uploads/attachment_data/file/727411/Public_health_control_ and_management_of_hepatitis_A_2017.pdf. Accessed 5 Apr 2019 